\title{
TESTING THE FLEXURAL FATIGUE BEHAVIOR OF E-GLASS EPOXY LAMINATES
}

\author{
Vijaykiran Bura ${ }^{1}$, Praveen.Dvr ${ }^{2}$ \\ ${ }^{I}$ Assistant professor, Mechanical Engineering, BVRIT Engineering college, Andhrapradesh, India. \\ ${ }^{2}$ Assistant professor, Mechanical Engineering, BVRIT Engineering college, Andhrapradesh, India
}

\begin{abstract}
With the advent of fiber reinforced composite materials the application of polymer composite materials is increasing in aerospace, marine and automobile fields, and non-conventional energy harvesting sectors in view of deriving advantages of polymer composites towards enhancing the equipment performance. Composites are replacing the conventional materials almost in every application. Due to their high specific strength, stiffness, better fatigue life, wear resistance and corrosion resistance. So polymer composites play a vital role in weight reduction with better functional characteristics of critical components like leaf spring, wheel drum, crash bumper etc. The tailor-designing capability with composite materials provides large scope of mechanical properties by adopting advanced design techniques. The tailored properties of laminated composite throws a challenge on design engineers to arrive at optimum design solutions. The flexural fatigue failure is common in rotating components such as wind turbine rotors and aero plane wing structures. The present work is focusing on flexural fatigue failure behavior with the help of flexural fatigue test rig established in the mechanical engineering department of JNTU. The explicit work publishes the experimental test results to understand the influence of frequency on the fatigue failure behavior due to cyclic flexing loads on the glass epoxy laminates
\end{abstract}

Keywords: fiber, flexure, matrix, composite, lamina, polymer

\section{INTRODUCTION}

\subsection{Need of Composite Materials}

Many of modern technologies require materials with unusual combinations of properties that cannot be met by the conventional metal alloys, and metals. This is especially true for material that are needed for aerospace, underwater, and transportation application. for example aircraft engineers are increasingly searching for structural materials that have low densities, strong, stiff, abrasion and impact resistant, and not easily corroded. This is rather formidable combination of characters. Frequently strong materials are dense also increasing the strength generally results in a decrease in impact strength. Material property combination materials, generally speaking, a composite considered to be a multi phase material that exhibits a significant proportion of properties of both constituent phases such that a better combination of property is realized, according to the principle of combined action, better property combinations are fashioned by the judicious combination of two or more distinct materials. Composite material is a material system composed of two or more dissimilar materials, differing in forms, and insoluble in each other, physically distinct and chemically inhomogeneous. The resulting products' properties are much different from the properties of constituent materials. A composite is combination of two materials in which one of the materials is called reinforcement, in the form of fiber, woven fabric sheets, or particles, embedded in the other materials called matrix. Composites are used because the overall properties of the composite are superior to those of the individual components. These are the following reasons why composites are selected for certain applications

\subsection{Properties of Composite Materials}

- High strength to weight ratio (low density, high tensile strength)

- High creep resistance

- High tensile strength at elevated temperatures

- High toughness

- High stiffness

- Non-flammable

- Good chemical resistant

- Relatively insensitive to moisture

- Good electrical insulation

- Able to maintain strength properties over wide range of conditions.

Typically, reinforcing materials are strong with low densities while the matrix is usually ductile, or tough, material. If the composite is designed and fabricated correctly, it exhibits the strength of the reinforcement with toughness of the matrix to achieve a combination of desirable properties not available in any single material.

\section{MATERIALS USED}

\subsection{Composites}

The idea is that by combining two or more distinct materials one can engineer a new material with desired combination of properties i.e. light in weight and strong. The idea that a 
better combination of properties can be achieved is called the principle of combined action. New high tech materials engineered to specific applications.

Usually composites are having two phases:

\section{Matrix phase}

2. Dispersed phase

Properties of composites depends on

1. Properties of phases

2. Geometry of dispersed phase i.e. particle size, distribution, orientation.

3. Amount of phase.

\subsection{Material}

Major constitutes in fiber reinforced composite materials are reinforcing fibers, and a matrix, which acts as a binder to the fibers. Other constituents that may also be found are coupling agents, coating and fillers. Coupling agents and coatings are applied on the fibers to improve their wetting with the matrix as well as to promote bonding across the fiber/matrix interface. Both in turn promote a better load transfer between the fibers and matrix. Fillers are used with some polymeric matrices primarily to reduce cost and improve the dimensional stability.

Manufacturing of composite structure starts with the incorporation of a large number of fibers in to a thin layer of matrix to form a lamina (ply). The thickness of the lamina is usually in the range of $0.1-1.2 \mathrm{~mm}$. If continuous fibers are used in making the lamina, they may be arranged either in a unidirectional orientation (i.e., fibers in one direction) or in a bi-directional orientation (i.e., fibers in two directions, usually normal to each other). For a lamina containing unidirectional fibers, the composite material has the high strength and modulus in the direction of the fibers. However, in the transverse direction, its strength and modulus can vary by employing various quantities as well as different types of fibers in the longitudinal and transverse directions. For a balanced lamina these properties are the same in both directions. A lamina can also be constructed using discontinuous fibers in a matrix. The fibers can be arranged either in unidirectional discontinuous or random discontinuous orientation.

Constituents In a composite

Fibres + Matrix + Coupling Agents or Coatings + Fillers

\subsubsection{Lamina}

(a) Unidirectional Continuous

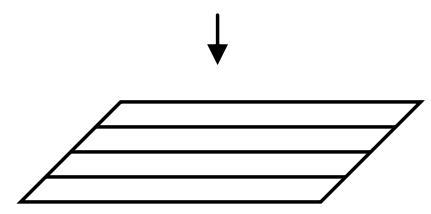

(b) Bidirectional Continuous

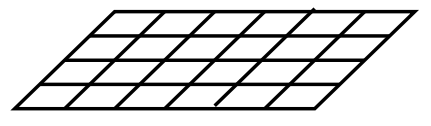

Unidirectional Discontinuous

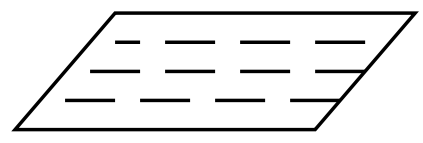

(c) Random Discontinuous

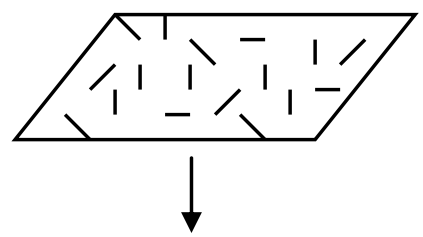

(d) Laminate

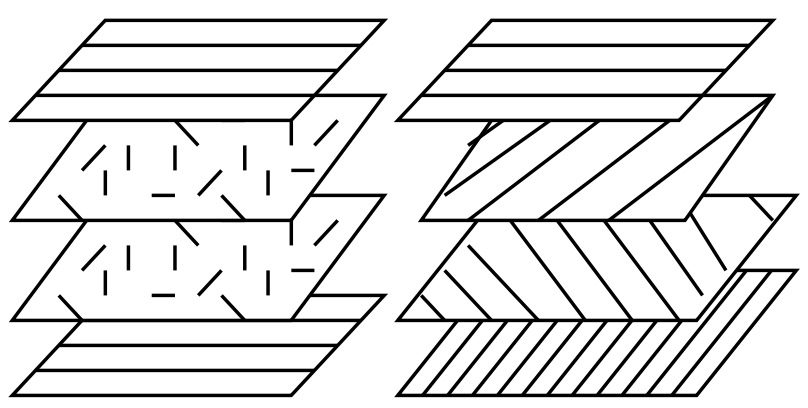

\subsubsection{Fiber}

Fibers are the principal constituent in a fiber-reinforced composite material. They occupy the largest volume fraction in a composite laminate and share the major portion of the load acting on a composite structure. Proper selection of the type, amount, and orientation of fibers is very important, since it influences the following characteristics of laminate:

- $\quad$ Specific gravity

- $\quad$ Tensile strength and modulus

- Compressive strength and modulus

- Fatigue strength as well as fatigue failure mechanisms

- $\quad$ Electrical and thermal conductivity

- Cost

Glass fibers are the most common of the all-reinforcing fibers for polymeric matrix composites (PMC). The principal advantage of glass fibers is low cost, high tensile strength, high chemical resistance and excellent insulating properties. The disadvantages are low tensile modulus, relatively high specific gravity and sensitivity to abrasion with handling (which frequently decreases its tensile strength).

- Typical properties of E-Glass:

- $\quad$ Typical diameter $-10 \mu \mathrm{m}$

- $\quad$ Specific gravity -2.54

- Tensile modulus - 73.4 Gpa

- Tensile strength - 3.45 Gpa

- Co efficient of thermal expansion $-5 e-6 /{ }^{\circ} \mathrm{C}$

- Poisson's ratio - 0.2

\subsubsection{Matrix}

The role of the matrix in a fiber-reinforced composite is (1) to transfer stresses between the fibers, (2) to provide a 
barrier against an adverse environment, and (3) to protect the surface of the fibers from mechanical abrasion. The matrix plays a minor role in the tensile load-carrying capacity of a composite structure. However, selection of a matrix has a major influence on the interlaminar shear as well as in-plane shear properties of the composite material. Among various matrix materials, thermoset polymers, such as epoxies (principally used in aerospace and aircraft applications) and polyesters (commonly used in automotive, marine, chemical and electrical applications), are in greatest commercial use, mainly because of the ease of processing with these materials.

Epoxy is one of the thermoset matrices. Starting materials for epoxy matrix are low-molecular-weight organic liquid resins containing a number of epoxide groups, which are three membered rings of one oxygen (o) and two carbon $(\mathrm{C}$ C) atoms. Epoxy matrix, as a class, has the following advantages over other thermoset matrices:

$>\quad$ Wide variety of properties, since a large number of starting materials, curing agents and modifiers are available

$>$ Absence of volatile matters during curve

$>$ Low shrinkage during cure

$>$ Excellent resistance to chemicals and solvents

$>$ Excellent adhesion to a wide variety of fillers, fibers and other substrates

The principal disadvantages are its relatively high cost and long cure time, when compared to polyester resin which has low viscosity, fast cure time, low cost and high volumetric shrinkage.

\subsection{E-Glass Fiber}

\subsubsection{Composition}

E-Glass is a low alkali glass with a typical nominal composition of

SIC---54\%wt

At20i-19\%wt

$\mathrm{CaO}+\mathrm{Mgo}-12 \% \mathrm{wt}$

BO------10\%wt

$\mathrm{Na} 20+\mathrm{K} 20$-less than $2 \% \mathrm{wt}$

And some other materials also present at impurity levels.

\subsubsection{Key Properties}

Properties that have made E-Glass so popular in fiber glass and other glass fiber reinforced composite include.

1. Low cost 2. High production rates 3 . High strength 4 . High stiffness 5. Relatively low density 6. Non-flammable 7. resistant to heat 8 . Good chemical resistant 9 . Relatively insensitive to moisture 10. Good electrical insulation 11. Able to maintain strength properties over wide range of conditions.

\section{EXPERIMENTAL SETUP}

\section{Introduction}

The flexural fatigue failure in laminated composite materials is a very common failure mode in most of the FRP components. As reinforced polymers used in weight critical applications, often over designing to compensate fatigue failure lead to the increase in weight which in turn hampers the objective of designer. In this connection the investigation on flexural fatigue failure behaviour of laminate to be used in the component is very important. As standard equipment and test procedures are not available the need for custom built flexural fatigue testing equipment arises. The design of flexural fatigue test rig is discussed in detail in the following sections.

\subsection{Flexural Fatigue Test-Rig Design}

FRP components like windmill blades, leaf spring and most of the components used in automobile industry are generally subjected to flexural fatigue. The present research work considers flexural fatigue is a critical property to be understood, while designing laminated composite components. In this connection efforts are in to designing and development of computer interfaced flexural fatigue test rig which is capable of storing the data related to the dynamic response of the laminate subjected to flexural fatigue. the schematic diagram furnished in the figure .This indigenous design consists few important components developed to test the composite laminates made as per the NASA contractors report specifications. These specifications of the laminate are made as per the same aspect ratio reported in the above mentioned reference.

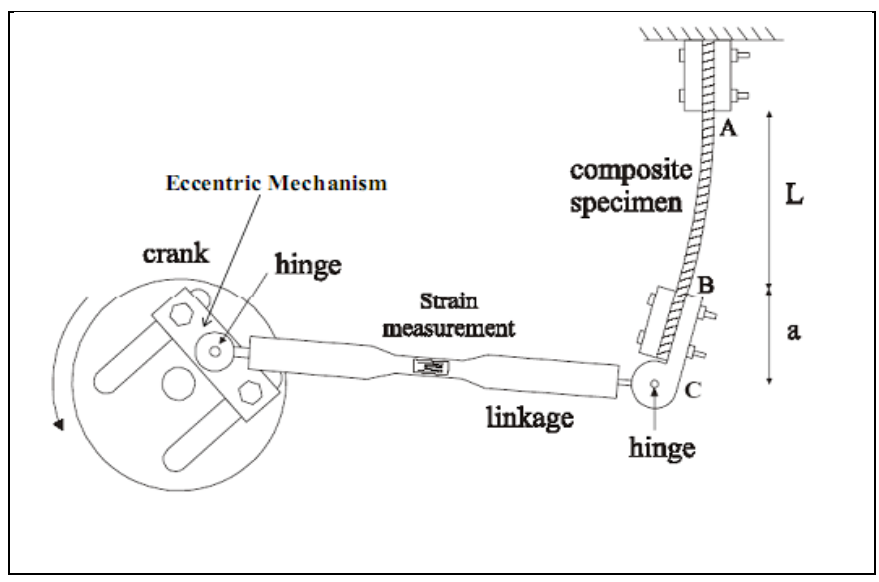

Fig 3.1: Schematic diagram of Test Rig

\subsubsection{Specifications of the Test-Rig}

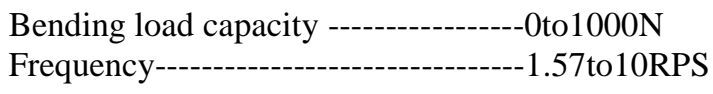

Specimen specifications

Length of Specimen--------100to 500mm

Width of Specimen---------30to50mm

Thickness of Specimen----2.5to10mm

Eccentricity---------------------------0to200mm

\subsubsection{Basic Components of Test Rig:}

These are the following important components of test rig: 
$1 \quad$ Load cell

2 Specimen holding beam

3 Dovetail assembly

4 Induction motor

5 Adjustable columns(sliding )

6 Electronic circuit(signal conditioning system)

7 Data acquisition system

\subsubsection{Load Cell}

Load cell is a component which senses load and delivers a voltage analog signal which is proportional to the intensity of load. This consists of a metallic body designed to meet the requirements of the working load range, generally made of aluminum alloy. The foil type Strain gauges are fixed to the body of the load cell. When the body of the load cell is subjected to load, the strain induced is transmitted to the strain gauge. Dynamic load sensor (LOAD CELL) is an important component of the test rig.

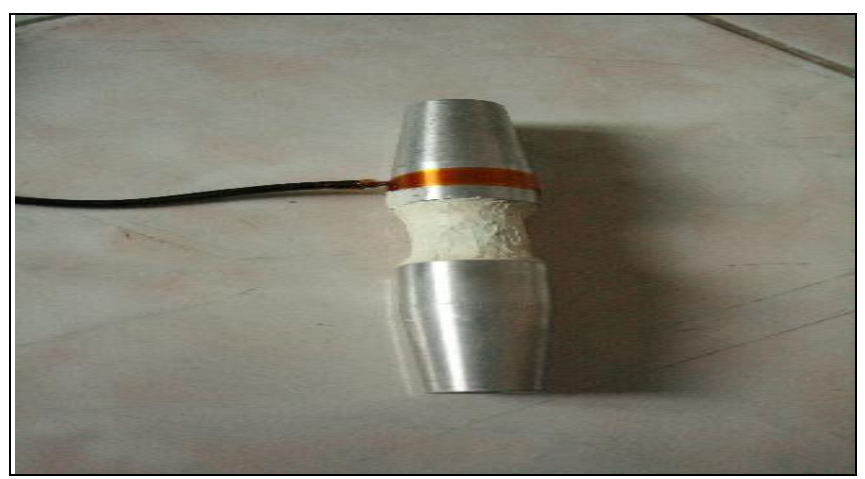

Fig 3.2: Load cell

\subsection{Data Acquisition System}

The data acquisition software is designed to sample the wave form to build the graphical representation of the analog signal arrived from the load cell based sensor circuit. In addition, provides the facility of storing the data facilitating the final analysis of observation.

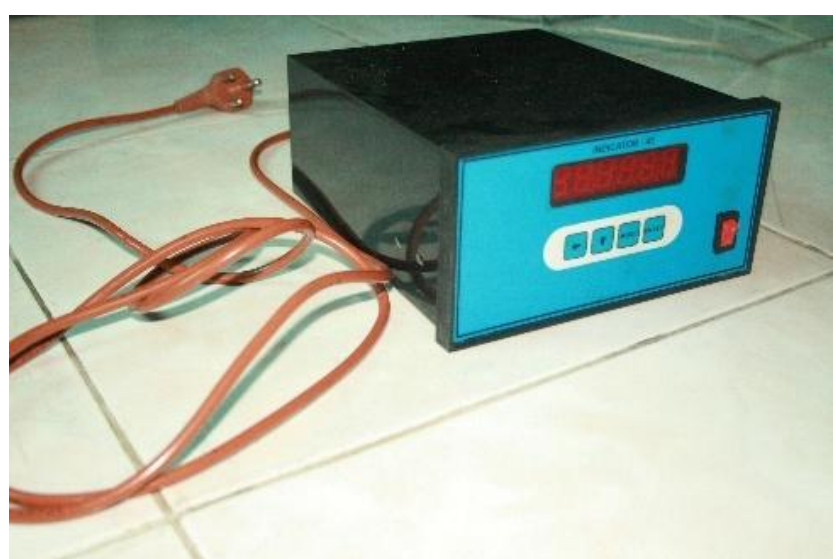

Fig 3.3: Signal Conditioning System for the Voltage Output from the Load Cell

In the above mentioned details of flexural fatigue-test rig the design of the load cell is a critical component of the test rig system. The design approach adopted in this work is furnished in the following sections.

\subsubsection{Specifications of the Data Acquisition System}

NI USB 6009: (National Instruments Make)

\section{Specifications: 8 Inputs, 14 bit Multifunctional}

DAC

\section{Analog Input}

Channels: 8 Single-ended input channels with 14bit resolution.

$>$ Range: Bipolar $\pm 5 \mathrm{~V}$.

$>$ Conversion Speed: 25 ì $\mathrm{S}$.

$>$ Accuracy: $0.015 \%$ of reading \pm 1 bit.

$>$ Linearity: \pm 1 bit.

$>$ Trigger Modes: Software trigger.

Data transfer: By program control

\section{Analog Output}

\section{DAC. Channel with 14-Bit Resolution.}

$>$ Ranges: 0 to $+5 \mathrm{~V}, 0$ to $+10 \mathrm{~V}$.

$>$ Setting time: $30 \mathrm{~S}$.

$>$ Linearity: $\pm 1 / 2$ bits.

$>$ Output drive: $\pm 5 \mathrm{mV}$ max.

The data logging system is an $\mathrm{M} / \mathrm{s}$ National Instrument make data acquisition card which is capable of sensing 750 samples per millisecond. The test rig is being run at 190 rpm, so a NI USB series 6009 student edition card has been selected which is capable of acquiring 45000 samples per second. This card acquires the data in form of voltage from the signal conditioning system to a magnitude of $10 \mathrm{~V}$ and plots a graph which is sinusoidal because of the alternating tensile and compressive loads acting on the specimen.

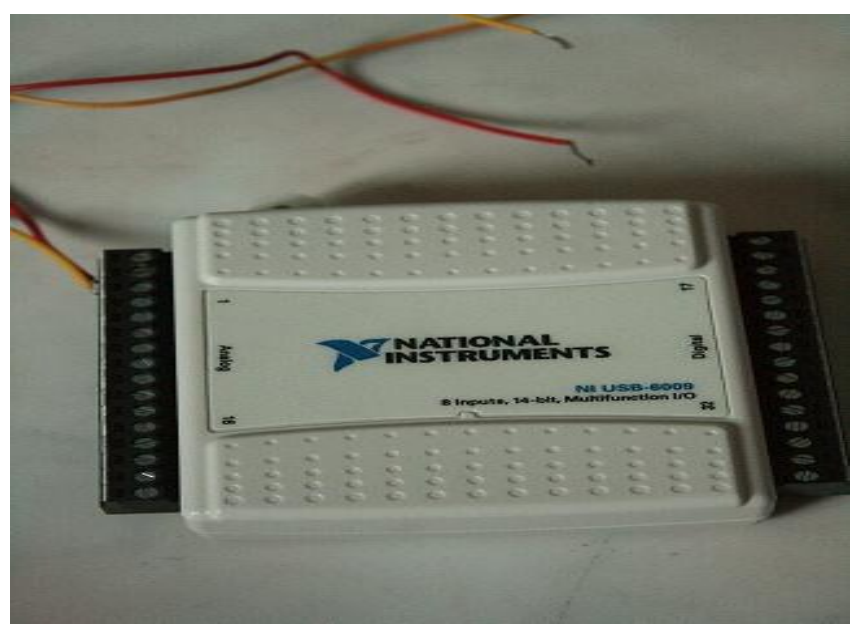

Fig 3.4: NI DAC USB 6009

The NI 6009 data logger stores the data in the system hard disk in the 'lab-view' format. By converting this data into compatible excel format will provide the excel graph sheets which can be read to understand the failure behaviour of the specimen. From these graphs failure behaviors can be 
modeled. There is a facility in the system that enables review of the logged data. In case the data generated is of large size then the data can be picked as per the programmed schedule in order to handle the data easily.

\subsection{Design and Fabrication of Load Simulating}

\section{Mechanism (Induction Motor):}

The 3H.P motor is incorporated in the test rig to provide sufficient torque and in turn provides sufficient bending load on the specimen.

\subsection{Power Transmission Device:}

The power transmission device used here is a heavy lathe head stock which is separated and supplied with power from a 3HP induction motor. The motor and the lathe head stock are connected using sufficient length V-belts which transmit the power from the motor to the head stock. The head stock is properly clamped to the bed on which it is placed to avoid any vibrations due to the applied load.

\subsection{Eccentric Mechanism:}

The eccentric mechanism is a system mounted on the head stock to convert the rotary motion of the head stock into translatory motion. The specimen is subjected to evenly distributed compressive and tensile loads, by this mechanism. One end cover holding the load cell is fixed to the eccentric mechanism. The eccentric mechanism is used to apply and gradually remove loads from the specimen during test procedures. The load being applied is displayed on the display provided on the signal conditioning system. A eccentricity locking mechanism has been provided on the king pin of the eccentric to prevent the sliding of king pin due to dynamic loads applied by the load cell. The explicit figure is furnished in the figure 4.2.

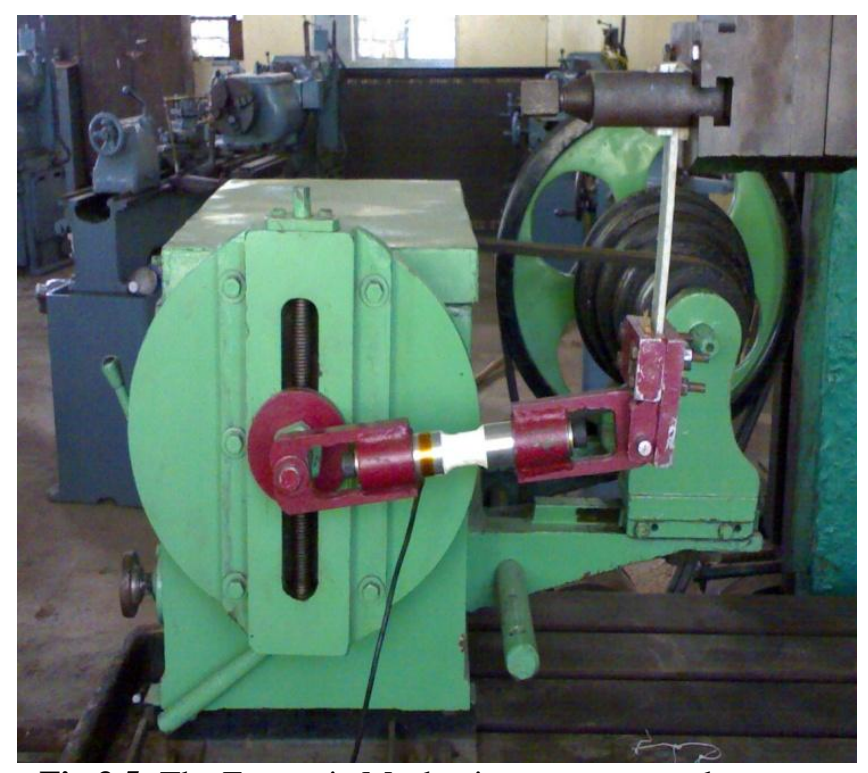

Fig 3.5: The Eccentric Mechanism to converts the rotary motion of the head-stock into translator motion

\subsection{Working principle of Test Rig:}

The schematic diagram of test is furnished in figure 3.2. The eccentric mechanism used is shown in the figure. The eccentric mechanism is driven by independent drive at speeds varying from 94RPM to 600RPM. The hinge eccentricity from the center of the crank is equivalent to the deflection induced in the composite specimen. This deflection resisting force is experienced by the linkage which is the dynamic load sensing sensor (strain gauge based load cell). The strain gauge bonded to the linkage (load cell) elongates and contracts along with the load cell which in turn imbalances the balanced bridge circuit connected to the strain gauge.

The output voltage of the bridge circuit is directly proportional to the deflecting load of the composite specimen. As eccentric mechanism rotates with the constant speed of 94 RPM, the strain measuring system develops voltage proportional to the degree of deflection. The voltage is in sinusoidal wave form. The cyclic load applied to the composite specimen generates a fatigue crack at the fixed end, which in turn reduces the stiffness of the composite specimen and that is been clearly reflected on the voltage output from the strain measuring bridge circuit. The amplitude of wave form decreases as the damage progresses in the due course as the cyclic loading proceeds from 0 cycles to $n$ number of cycles. This diminishing wave form reveals the health of the laminate as the time progresses. The recorded data is analyzed to understand the fatigue failure behavior of the laminate.

The objective of the test rig is simulating desired reversed cyclic bending load on the composite laminate which is fixed vertically as shown in figure 4.2. The bending load is measured from the signals of load cell. The eccentric mechanism is rotated through the head stock-pulley system by 3 horse power induction motor. Through this pulley system the rotating speed obtained is 1.57 RPS. The signal continuously coming from load cell is fed to signal conditioning system to amplify the signal to a readable extent. The signal conditioning system is capable of amplifying and conditioning the signal precisely. This analog signal is proportional to the load applied on the composite specimen. The signal is fed to the NI 6009, data logger with 8 channels. The lab view software continuously logs the data and stores the data in hard disk, as the data generated and logged is very huge. The lab view software provides a facility to capture the data in the form of snap shots. As the data logging system has the capability of sampling frequency of 48 kilo samples per second. As the frequency of loading cycles is 1.57 RPS, a 3.33 seconds snap shot could not be plotted as a complete cycle of loading, the sampling frequency has been reduced to 300 samples per second. The snap shot data can be exported to excel format. The typical sample in excel format is furnished below in the table 3.1.The sample front end of the lab view soft ware during experiment is furnished in the figure 3.8 and the snap shot data exported to excel could be plotted as shown in the figure 3.9. The data represented in this figure has to be further processed i.e. conversion from 
time vs. voltage data should be converted into load in Newton vs. number of cycles of load application.

Table 3.1: The sampled data in the form of time vs. voltage

\begin{tabular}{|c|c|}
\hline Date & \#\#\#\#\#\#\#\# \\
\hline Time & $12: 07: 42$ \\
\hline Y_Unit_Label & Voltage $(V)$ \\
\hline X_Dimension & Time $(s)$ \\
\hline$X 0$ & $0.00 E+00$ \\
\hline Delta_X & 0.003333 \\
\hline \multicolumn{2}{|c|}{ ***End_of_Header $* * *$} \\
\hline X_Value & $\begin{array}{l}\text { 12/1/2008: } \\
\text { 12:07:36 PM- } \\
\text { Voltage } \\
\text { Dev1_ai0 }\end{array}$ \\
\hline 0 & $-0.97 \overline{7} 09$ \\
\hline 0.003333 & -0.99495 \\
\hline 0.006667 & -1.02173 \\
\hline 0.01 & -1.03958 \\
\hline 0.013333 & -1.06254 \\
\hline 0.016667 & -1.07146 \\
\hline 0.02 & -1.08804 \\
\hline 0.023333 & -1.09569 \\
\hline 0.026667 & -1.11227 \\
\hline 0.03 & -1.11865 \\
\hline 0.033333 & -1.1314 \\
\hline 0.036667 & -1.13395 \\
\hline 0.04 & -1.1365 \\
\hline 0.043333 & -1.13905 \\
\hline 0.046667 & -1.13905 \\
\hline 0.05 & -1.1416 \\
\hline 0.053333 & -1.1416 \\
\hline 0.056667 & -1.12885 \\
\hline
\end{tabular}

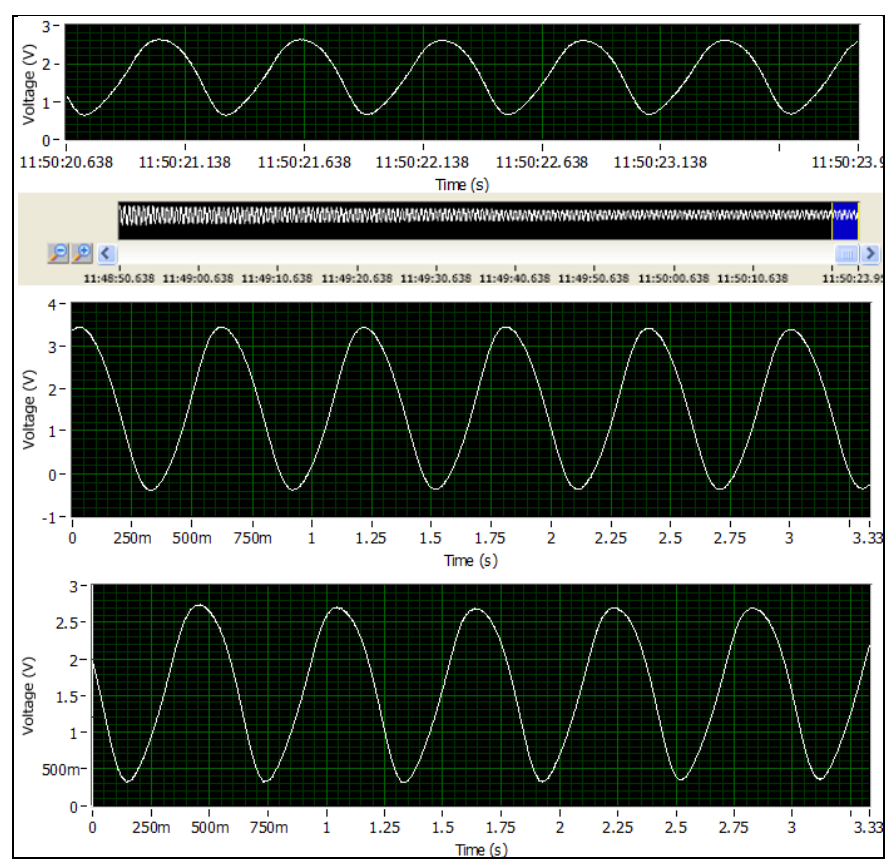

Fig 3.6: The front end of lab view soft ware

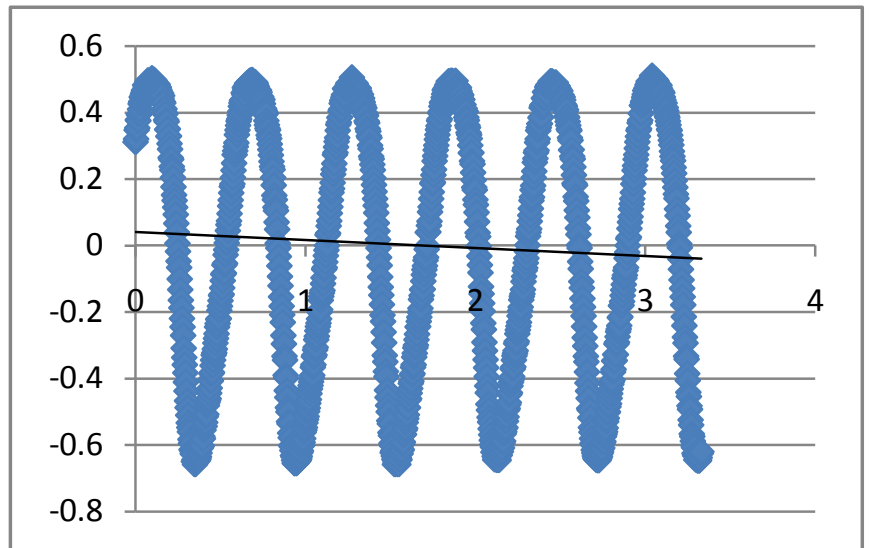

Fig 3.7: Excel plot of snap shot data voltage vs. time for 3.33 seconds

\section{FLEXURAL FATIGUE EXPERIMENTATION}

\subsection{Experimental Procedure}

These days lot of research is directed to understand the fatigue failure behavior of laminated composites. These materials usage is increasing in all sorts of engineering applications due to high specific strength and stiffness. Fibre reinforced composite materials are selected for weight critical applications and these materials have good rating as per the fatigue failure is concerned. Composite materials are anisotropic in nature and their failure behaviour is different from that of isotropic materials. Present research work is aimed at analyzing the flexural fatigue behavior of laminated composites at varying speeds i.e., at 90 RPM, 127 RPM and 200 RPM . The design of flexural fatigue test rig is discussed in detail in the chapter No.3. The data generated from the test rig is logged and analyzed for further investigation, to understand the failure behaviour of laminated composites of Glass- epoxy. From the literature, most of the research work is reported on specimens made by resign transfer moulding technique. This process has a constraint in, achieving beyond $50 \%$ and higher volume fraction of reinforcement. It is difficult for this reason the present work is aimed at establishing flexural fatigue characteristics of higher volume fraction of reinforcement loading in the ranges of $68 \%$ to $75 \%$ volume fraction. The volume fraction of reinforcement is one of the important parameters which influence the flexural fatigue failure characteristics. In view of further optimizing the designs, during this work, an attempt is made to establish the flexural fatigue characteristics of laminates with higher reinforcement usage of $65 \%$ to $75 \%$ volume fraction of reinforcement.

\subsection{Loading Criteria for Flexural Fatigue Analysis of Glass Epoxy Laminate}

For simulating high cycle flexural fatigue on the test coupons, the coupons are made as per NASA contractor's report. The calculations were made to estimate the bending loads considered to simulate stresses of the order of $50 \%$ of maximum tensile strength. To estimate the bending load, tensile tests were carried out on laminates made as per 
ASTM D-638 specifications. The tensile test results of specimens of $[ \pm 0]_{8},[ \pm 20]_{8},[ \pm 30]_{8},[ \pm 40]_{8},[ \pm 45]_{8},[ \pm 55]_{8} \&$ $[ \pm 60]_{8}$ degree orientation are furnished and only given the results because of the space constraints.

And the corresponding bending loads to be applied are calculated with reference to the beam bending equation.

$$
\mathrm{M} / \mathrm{I}=\mathrm{F} / \mathrm{Y}
$$

The specimen is fixed to fatigue testing rig in cantilever mode, then the Maximum bending moment $\mathrm{M}=\mathrm{WL}$ where $\mathrm{W}$ is the bending load applied on the specimen. The distance from the neutral axis to the surface of specimen is Y, which is equal to half the thickness of the specimen.

$$
\mathrm{Y}=\mathrm{t} / 2
$$

Moment of Inertia of the specimen $\mathrm{I}=\mathrm{bh}^{3} / 12$ and

Bending stresses induced in the specimen

$\mathrm{F}=1 / 2$ (Ultimate Tensile strength of the specimen)

Form the above theory; bending load for each specimen is obtained.

\subsection{Tensile Test and its Significance to Perform Flexural Fatigue Experiment}

Tensile tests were performed on balanced symmetric laminates of $[ \pm 0]_{8},[ \pm 20]_{8},[ \pm 30]_{8},[ \pm 40]_{8},[ \pm 45]_{8},[ \pm 55]_{8}$ \& $[ \pm 60]_{8}$ degree orientation. The tensile test were performed on the laminates which are made as per the ASTM D-638 specifications

The test was performed in the CIPET, Hyderabad laboratories and saint GOBAIN VETROTEX India private Ltd. quality control laboratories, Hyderabad and DRDL Hyderabad laboratory. The consolidated test results are furnished in table 5.1.

The modulus of elasticity has been calculated at $0.5 \%$ strain

\subsection{Methodology Adopted to Conduct Flexural}

\section{Fatigue Analysis}

In the present work, close aspect is ratio is maintained in the specimen manufacture following NASA contractor's report. Most of researchers discussed about flexural fatigue behaviour of $[ \pm 0]_{8},[ \pm 45]_{8} \&[ \pm 90]_{8}$ degree orientation. In the present work tests were performed on $[ \pm 0]_{8},[ \pm 20]_{8}$, $[ \pm 30]_{8},[ \pm 40]_{8},[ \pm 45]_{8},[ \pm 55]_{8} \&\left[ \pm 60{ }_{8}\right.$ degree orientation. In view of having a broad spectrum of data bank regarding flexural fatigue failure behaviour, the flexural loading aspects are derived from the calculations with reference to the tensile test results.

\subsection{Criterion for Conducting Flexural Fatigue Test}

The specimen of $140 \mathrm{~mm}$ long $35 \mathrm{~mm}$ width and $5.85 \mathrm{~mm}$ thick are subjected to flexural fatigue test. The fluxing load to be applied on the specimen is considered from the tensile test results conducted on the specimens prepared from the same laminate used for the fatigue test. The tensile test results are furnished in the table 5.1. The maximum tensile strength is the basis for the bending load to be applied on the specimen. The bending load to be applied on the specimen is arrived from the calculations based on bending equation, such that, the stresses due to bending are equivalent to $50 \%$ of the stresses of maximum tensile strength of the laminate. The deflection to be simulated is estimated by conducting deflection test on the specimens in the following section 5.5.1.

Table 4.1: Tensile Test Results.

\begin{tabular}{|l|l|l|}
\hline $\begin{array}{l}\text { Sample orientation } \\
\text { sequence in deg } \\
\text { (CROSSPLY) with } \\
\text { eight layers }\end{array}$ & $\begin{array}{l}\text { Max Tensile } \\
\text { strength in } \\
(\mathrm{MPa})\end{array}$ & $\begin{array}{l}\text { Modulus } \\
0.50 \% \\
\text { in(GPa) }\end{array}$ \\
\hline$\left[ \pm 0^{0}\right]_{8}$ & $\begin{array}{r}\text { at } \\
\text { Strain }\end{array}$ \\
\hline$\left[ \pm 20^{0}\right]_{8}$ & 358 & 37.96 \\
\hline$\left[ \pm 30^{0}\right]_{8}$ & 288 & 30.22 \\
\hline$\left[ \pm 40^{0}\right]_{8}$ & 170 & 18.9 \\
\hline$\left[ \pm 45^{0}\right]_{8}$ & 65 & 10.21 \\
\hline$\left[ \pm 55^{0}\right]_{8}$ & 74.3 & 10.54 \\
\hline$\left[ \pm 60^{0}\right]_{8}$ & 113. & 10.89 \\
\hline
\end{tabular}

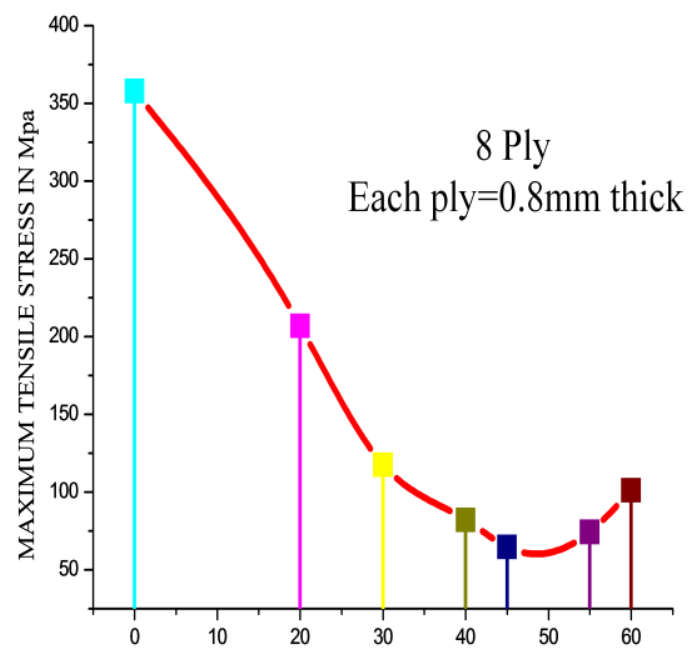

ORIENTATION IN DEGREES OF THE LAMINATES IN CROSSPLY

Fig 4.1: Orientation Sequence of Stacking versus Failure Stress.

\subsubsection{Experimental Setup for Deflection Test}

The deflection to be induced in the specimen is estimated by conducting the deflection tests on the specimens of laminates $[ \pm 0]_{8},[ \pm 20]_{8},[ \pm 30]_{8},[ \pm 40]_{8},[ \pm 45]_{8},[ \pm 55]_{8} \quad$ and $[ \pm 60]_{8}$. The photograph of the experimental setup is shown in Figure 5.2 and the schematic diagram is shown in the Fig.No.5.3.The experimental set up is instrumental in estimating the deflection to be induced to simulate the 
required bending stress in the specimen subjected to flexural bending.

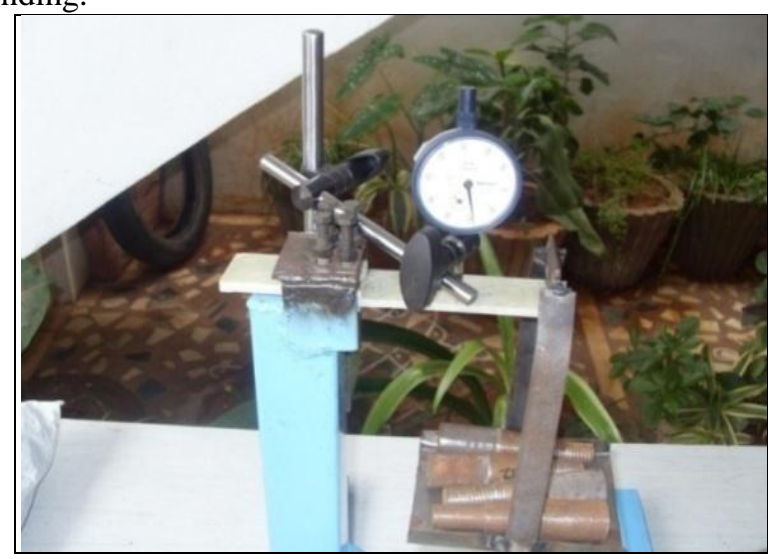

Fig 4.2: Experimental setup for deflection test.

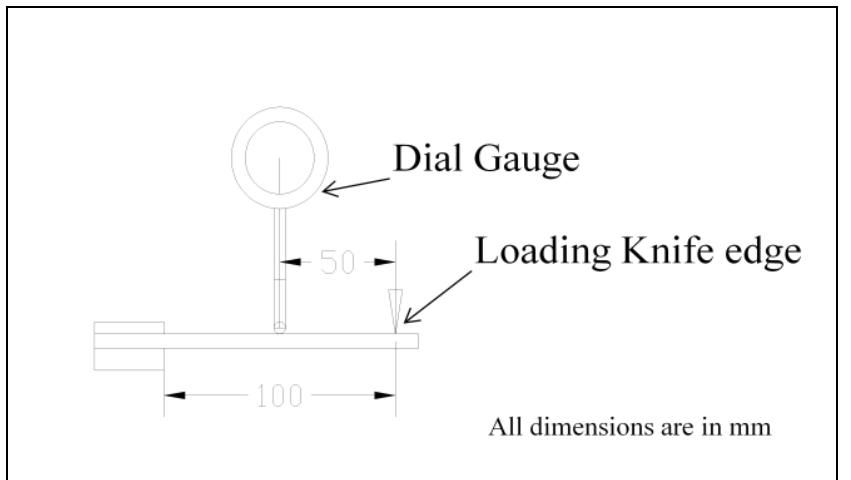

Fig 4.3: Schematic representation of deflection experimental set up.

Making use of the Experimental setup, deflection test is performed on the $\left.[ \pm 0]_{8},[ \pm 20]_{8},[ \pm 30]\right]_{8},[ \pm 40]{ }_{8},[$ $\pm 45]_{8},[ \pm 55]_{8}$ and $[ \pm 60]_{8}$ specimens. As the total load could not be simulated on deflection test due to experimental setups' geometrical constraints, the experimental results were extrapolated to estimate actual deflection. This is done origin lab software. The deflection test results and estimated deflection are furnished in the following sections 5.5.1 (a) to (g) on the specimens .The specifications of these specimens are furnished in the table 4.2 .

Table 4.2: Specification with respect to the orientation of stacking

\begin{tabular}{|l|l|l|l|l|}
\hline S.No ofTest & $\begin{array}{l}\text { Sample orientation sequence in } \\
\text { deg (CROSSPLY) }\end{array}$ & $\begin{array}{l}\text { effective length of } \\
\text { specimen in m. }\end{array}$ & $\begin{array}{l}\text { thickness of specimen } \\
\text { in mm }\end{array}$ & $\begin{array}{l}\text { number of } \\
\text { layers }\end{array}$ \\
\hline $\mathrm{a}$ & {$\left[ \pm 0^{0}\right]$} & $100 \mathrm{~mm}$ & $5.85 \mathrm{~mm}$ & 8 \\
\hline $\mathrm{b}$ & {$\left[ \pm 20^{0}\right]$} & $100 \mathrm{~mm}$ & $5.85 \mathrm{~mm}$ & 8 \\
\hline $\mathrm{c}$ & {$\left[ \pm 30^{0}\right]$} & $100 \mathrm{~mm}$ & $5.85 \mathrm{~mm}$ & 8 \\
\hline $\mathrm{d}$ & {$\left[ \pm 40^{0}\right]$} & $100 \mathrm{~mm}$ & $5.85 \mathrm{~mm}$ & 8 \\
\hline $\mathrm{e}$ & {$\left[ \pm 45^{0}\right]$} & $100 \mathrm{~mm}$ & $5.85 \mathrm{~mm}$ & 8 \\
\hline $\mathrm{f}$ & {$\left[ \pm 55^{0}\right]$} & $100 \mathrm{~mm}$ & $5.85 \mathrm{~mm}$ & 8 \\
\hline $\mathrm{g}$ & {$\left[ \pm 60^{0}\right]$} & $100 \mathrm{~mm}$ & $5.85 \mathrm{~mm}$ & \\
\hline
\end{tabular}

Deflection and eccentricity induced in the test-rig with respective to the specimen is furnished in the Table No.4.3. This table consists of deflection to be induced on the specimen by considering the effective length of $210 \mathrm{~mm}$ which is the sum of effective length of the specimen $100 \mathrm{~mm}$ and the $110 \mathrm{~mm}$ length from the centre of the pivoting pin to the specimen fixed end, as shown in the Fig. No 5.12. The consolidated statement of specimen's mechanical properties and load to be simulated as per the considerations are furnished in the Table No.4.4.

Table 4.3: Deflection and eccentricity induced in the specimen

\begin{tabular}{|c|c|c|c|c|c|}
\hline $\begin{array}{l}\text { Sample orientation } \\
\text { sequence in Deg. } \\
\text { (Crossply) }\end{array}$ & $\begin{array}{l}\text { Bending Load } \\
\mathrm{F}_{0}=\text { WinNewton }\end{array}$ & $\begin{array}{l}\text { Bending } \\
\text { Stresses to be } \\
\text { inducedMPa. }\end{array}$ & $\begin{array}{lr}\text { Max } & \text { Tensile } \\
\text { strength } & \text { in } \\
(\mathrm{MPa}) & \end{array}$ & $\begin{array}{l}\text { EffectiveDeflection } \\
\delta \text { induced at on } \\
\text { specimen in } \mathrm{mm}\end{array}$ & $\begin{array}{l}\text { Tensile } \\
\text { modulus } \\
\mathrm{E}_{\mathrm{xx}} \\
\mathrm{GPa} .\end{array}$ \\
\hline$\left[ \pm 0^{0}\right]_{8}$ & 320 & 179 & 358 & 20.517 & 37.96 \\
\hline$\left[ \pm 20^{0}\right]_{8}$ & 318 & 144 & 288 & 21.735 & 30.33 \\
\hline$\left[ \pm 30^{0}\right]_{8}$ & 175 & 85 & 170 & 14.64 & 18.9 \\
\hline$\left[ \pm 40^{0}\right]_{8}$ & 171 & 81 & 162 & 14.16 & 10.21 \\
\hline$\left[ \pm 45^{0}\right]_{8}$ & 80 & 32.5 & 65 & 10.07 & 10.54 \\
\hline$\left[ \pm 55^{0}\right]_{8}$ & 80 & 37.15 & 74.3 & 10 & 10.89 \\
\hline$\left[ \pm 60^{\circ}\right]_{8}$ & 120 & 56.5 & 113 & 20.44 & 10.86 \\
\hline
\end{tabular}


Table 4.4: The consolidated statement of specimen's mechanical properties and load simulated on by the test rig.

\begin{tabular}{|l|l|l|l|l|}
\hline $\begin{array}{l}\text { Sample orientation } \\
\text { sequence in deg } \\
(\text { CROSSPLY) }\end{array}$ & $\begin{array}{l}\text { Maximum Tensile } \\
\text { Strength In MPA }\end{array}$ & $\begin{array}{l}\text { Load Applied In } \\
\text { Kgs To Induce 50\% } \\
\text { Bending Stresses } \\
\text { With Respect To } \\
\text { Maximum Tensile } \\
\text { Strength }\end{array}$ & $\begin{array}{l}\text { Thickness Of } \\
\text { Specimen In mm }\end{array}$ & $\begin{array}{l}\text { Volume Fraction Of } \\
\text { Glass Reinforcement }\end{array}$ \\
\hline$\left[ \pm 0^{0}\right]_{8}$ & $32.5 \mathrm{kgs}$ & $5.85 \mathrm{~mm}$ & 0.73 \\
\hline$\left[ \pm 20^{0}\right]_{8}$ & 358 & $31.8 \mathrm{kgs}$ & $5.85 \mathrm{~mm}$ & 0.73 \\
\hline$\left[ \pm 30^{0}\right]_{8}$ & 288 & $16.1 \mathrm{kgs}$ & $5.85 \mathrm{~mm}$ & 0.73 \\
\hline$\left[ \pm 40^{0}\right]_{8}$ & 170 & $17.15 \mathrm{kgs}$ & $5.85 \mathrm{~mm}$ & $0 . .73$ \\
\hline$\left[ \pm 45^{0}\right]_{8}$ & 162 & $5.3 \mathrm{kgs}$ & $5.85 \mathrm{~mm}$ & 0.73 \\
\hline$\left[ \pm 55^{0}\right]_{8}$ & 65 & $8 \mathrm{kgs}$ & $5.85 \mathrm{~mm}$ & 0.73 \\
\hline$\left[ \pm 60^{0}\right]_{8}$ & 74.3 & $12 \mathrm{kgs}$ & $5.85 \mathrm{~mm}$ & 0.73 \\
\hline
\end{tabular}

\subsection{Load Simulation on Test Rig}

The assembly of eccentric mechanism is provided in such a way that complete reversible bending on the test specimen fixed in cantilever mode is applied. The specification of the specimen is shown in figure 5.11. The schematic diagram of Flexural Fatigue Bending Loading mechanism is shown in figure 5.12. By rotating the eccentric mechanism with the help of electric motor, cyclic bending is applied on the specimen of a frequency of 1.57 cycles/sec. The bending load is sensed by the sensor (load cell).The signal generated from the load cell is amplified to an extent of fraction of mille volts to volts, which is proportion to the load. The sensor strain gauges used in the setup are of Iso-elastic type. This type of strain gauges instantaneously responds to the load applied on the load cell. The voltage generated is sent to the USB compatible National Instruments made 6009 data logger through signal conditioning system, which is capable of sampling 1000 samples per second. With this capacity the data is logged and fed to the computer hard disk with the help of LAB VIEW software. The large quantity of data generated from the test coupons could not be handled because of limitations of windows based excel software which could not handle more than 64,000 numbers of data points. In this situation, snapshots were collected at regular time intervals. Each snapshot consists of 1000 data points for a period of 3.33 seconds.

The test is performed continuously for a period of more than 4 hrs depending on the specimen's specifications (orientation sequence of reinforcement in the laminate). As the test is conducted for hours together; it has been observed that there is creep in the data generation. The creep is normally due to heating of strain gauges. In order to remove that creep dynamic calibration technique has been adopted.

The present experimental work is focusing on flexural fatigue analysis of 0.73 volume fraction glass fiber loaded test coupons, as this grade of fibre loading is generally achieved in filament wound products and Vacuum Bag cured products. The following sections briefly discusses about the design of the test rig and also discusses the method of data processing and interpreting the data by presenting the data in the form of stiffness degradation curves. Before proceeding to the flexural fatigue experimentation, calibration and testing of the load cell was carried out and the information related to system terminology, the details related to electrical wiring were discussed in detail in the Chapeter-4 Under section 4.3and 4.4.

\subsection{Working of the Test Rig System}

The present work is aimed at establishing a standard test procedure for analyzing and understanding the flexural fatigue failure behaviour of composite laminates. Composite materials' failure behaviour is very complex when compared to the conventional isotropic materials due to the influence of matrix-reinforcement interfacial relations and the polymer matrix fracture behaviour. Considering these factors, the test-rig is designed to continuously monitor the health of the laminate throughout the test. The capability of the test-rig critically depends on the dynamic load sensing transducer and data logging system. The data generated from the test rig's data logger could be analyzed to predict fatigue life characteristics of composite laminates.

The strain measuring sensing element in the load cell is of Electrical type. The Strain gauge is glued to the Load cell. The Resistance of the strain gauge is $350 \mathrm{ohms}$ under unstrained conditions. These strain gauges are incorporated in the Bridge circuit. This Bridge is excited by 10 Volts DC supply. Under no load condition the bridge is under balanced condition. When load is applied on the load cell, the dimensions of strain gauge gets changed thereby its resistance is varied. The amount of strain applied on the load cell proportionally changes the resistance of the strain gauge. This change in resistance causes the bridge unbalance. This unbalanced voltage is proportional to the load applied on the specimen. 
The unbalanced voltage from bridge is of low magnitude which is very difficult to sense, which is fed to Instrumentation amplifier. The advantage of Instrumentation amplifier over a general amplifier is that it eliminates offset voltages from the signal voltage. A general Instrumentation amplifier amplifies both signal and offset voltages whereas Instrumentation amplifier nullifies the offset and amplifies the signal alone. The amplified signal will be disturbed by the power line pickups (i.e., $50 \mathrm{~Hz}$ ) and other electromagnetic interferences. The effects of noise are filtered by a low pass filter whose higher cutoff frequency is less than $50 \mathrm{~Hz}$. The filtered signal is an analog one and it is to be converted into digital mode.

\subsection{Flexural Fatigue Test Rig Interfacing with Data}

\section{Logging System}

The specimens are fixed vertically to a rigid platform as shown in Figure 5.12. The dynamic load sensor is fixed to the specimen through a hinge as represented in the schematic diagram 4.2.The dynamic load sensor's other end is assembled to the pivot of the eccentric mechanism. The eccentricity is provided based on the deflection load calculations made from the experimental results. On rotating the eccentric mechanism by one revolution, a complete symmetrical reversible bending about the neutral axis of the laminate is induced. The deflection force is measured from the signal condition system digital display. The induced load is estimated in view of providing bending stress on the laminate, the stresses were kept $50 \%$ below the yield strength of the individual laminates. The bending loads are estimated from the tensile test results of the respective laminates $[ \pm 0]_{8},[ \pm 20]_{8},[ \pm 30]_{8},[ \pm 40]_{8},[ \pm 45]_{8},[ \pm 55]_{8}$ and $[ \pm 60]_{8}$ the frequency of cyclic loading is of $1.57 \mathrm{HZ}$. As the eccentric mechanism is rotating the bending load is measured in the indirect from of voltage generated from the dynamic load sensor. The NI 6009 data logger with 8 channel analog and digital signal receiving capability has been used to $\log$ the data generated from the load sensor. The voltage generated from the load sensor is conditioned by a signal condition system and then the analog output from the signal condition systems is fed through the date logger to PC. The LAB VIEW software provided by' National Instruments' is used to log the data in the form of time versus voltage. As the cyclic loading is applied on specimen is converted in the form of a perfect sinusoidal voltage wave form is stored in the PC in the LAB VIEW file format. As the test is continuously performed on the specimen the continuous data points of voltage and time are stored in the PC.

The LAB VIEW software has the provision of collection of snapshot for a period of $3.33 \mathrm{sec}$. And then there is a provision of exporting the data into EXCEL format in the form of time versus voltage data points. Number of such snap shots in regular intervals of one snap shot for 30 second's are taken and exported to EXCEL file format, from the beginning of the test to end of the test.
The test is stopped when the residual stiffness of the laminates is almost constant after number of cycles of fatigue loading. It has been observed from the test that the stiffness of the test coupon is continuously degrading due to the failure of the top and bottom layers because of cyclic loading. Once few layers of the top and bottom layers of laminate are damaged, the continuous redistribution of stresses lead to the prevention of further damage due to pivoting effect occurrence in the laminate. Once this state is reached further reduction in stiffens observed is almost zero.

\subsection{Specifications of the Flexural Fatigue Specimen}

Flexural fatigue specimens are prepared as per specifications mentioned in reference [94]. Flexural fatigue specimens are made by compression moulding technique. The methodology of moulding the specimens is mentioned in the chapter No.3. With reference to the NASA report the thickness of the specimen is $2.5 \mathrm{~mm}$, the width is $35 \mathrm{~mm}$ and the effective length is $50 \mathrm{~mm}$. In the present experimental work for holding the specimen in the flexural fatigue test rig, the effective length is increased to $100 \mathrm{~mm}$ and in the same proportion the thickness is increased to $6 \mathrm{~mm}$. The geometry of the specimen is shown in figure 5.11.

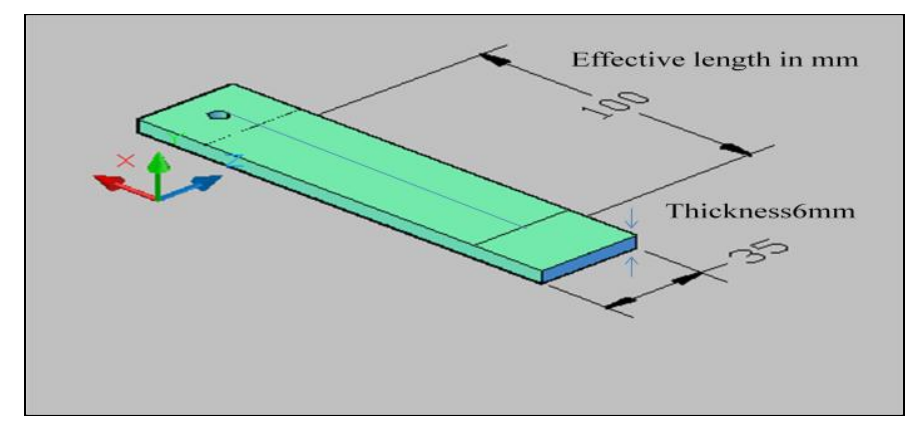

Fig 4.4 Specifications of flexural fatigue specimen

To prevent the specimen slipping from the specimen holder due to dynamic loads, a $6 \mathrm{~mm}$ bolt is passed through the specimen holding clamp. The bolt will passes through the specimen.

\subsection{Estimation of Bending Load to be Simulated}

\section{for Conducting Flexural Fatigue Analysis}

The basic definition of high cyclic fatigue is that the stresses induced due to cyclic loading should be well below the $50 \%$ of the ultimate tensile stresses (strength) in the specimen subjected to fatigue loading. The present work is focusing on flexural fatigue analysis of glass epoxy balanced symmetric laminates. In view of simulating such stresses the following calculations provide the estimation of bending loads to be simulated on specimens.

Let $\mathrm{M}=$ Bending Moment $=\mathrm{W}^{*} \mathrm{~L}$ (Where $\mathrm{W}$ is the bending load and $\mathrm{L}$ is the effective length of the specimen) $\mathrm{f}=$ Bending Stresses 
And $\mathbf{I}=$ Moment of Inertia of the specimen $=\mathrm{bt}^{3} / 12$, where ' $b$ ' is the width of the specimen and 't' is the thickness of the specimen.

The load to be simulated is estimated from classical bending beam equation i.e., $\mathrm{M} / \mathrm{I}=\mathrm{f} / \mathrm{Y}$, Where $\mathrm{f}$ is the bending stresses to be simulated as per the definitions of high cyclic fatigue loading. And ' $\mathrm{Y}$ ' is the half the thickness of the specimen.

The bending load could be estimated by the following formula, $\mathrm{W}=\mathrm{f} \mathrm{I} / \mathrm{LY}$.

The table 4.3 provides the necessary bending load to be simulated on the specimen and also the required deflection to be induced in the flexural fatigue analysis.

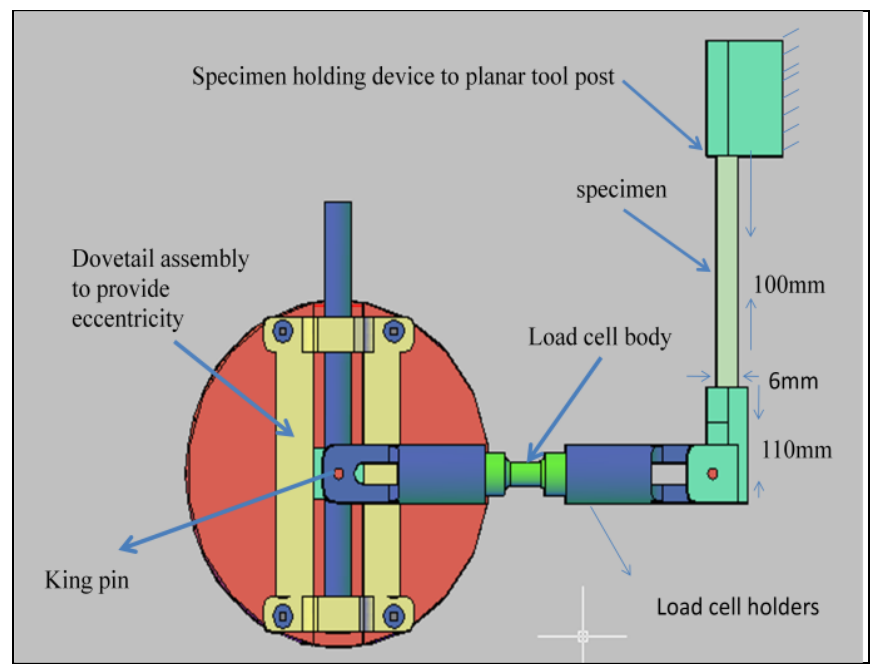

Fig 4.5: Flexural Fatigue Bending Loading mechanism

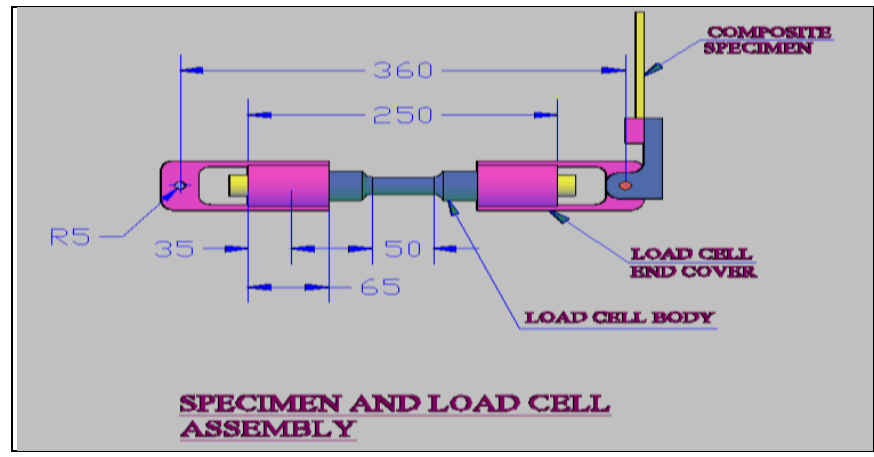

Fig 4.6: Specimen and load cell assembly

\subsection{Data Processing}

The data collected in the EXCEL format (files) are further processed, as there are constraints in the electronic equipment functional behaviour such as "creeping of strain gauge resister's resistance" and overheating of the signal condition system's electronic circuits, over a period of time lead to a faulty data generation in the form of offset voltage. This offset voltage is subtracted from data collected in each snapshot, this task is dynamic calibration. one data point is collected pertaining to the first peek of the sinusoidal wave form from each snap shot data, then from all these points time versus voltage curve is obtained by plotting all these data points. As the voltage is proportional to the load falling on the specimen, the voltage has been converted into load in Newton's and plotted in the form of time versus load which is representing the instantaneous stiffness of the laminate corresponding to the time, then this curve once again converted onto no of cycles versus time by converting time into number of cycles by multiplying with the frequency of cyclic load application.

The following figures $1,2,3,4,5,6$ and 7 represents the stiffness degradation curve of lamina subjected to flexural fatigue. The specifications of the lamina tested were arrived with reference to the NASA research report Ref No.[94] The specimen's specifications were with similar aspect ratio mentioned in the NASA research report i.e., similar L: $t$ ratio.

\subsection{Stiffness Degradation Curve Plotting and}

\section{Fitting}

Flexural fatigue failure behaviour of laminates exhibit stiffness decay with respect to number of cycles of load application. In this work ORIGIN LAB curve fitting tool is used to plot the data, number of cycles versus instantaneous maximum bending load within the cycle. Exponential decay first order curves were fitted to the experimental data in order to understand the failure behaviour.

The model equation is as follows

$$
\mathbf{Y}=\mathbf{Y}_{0}+\mathbf{A}_{1} \mathbf{e}^{-\mathrm{x} / \mathrm{t}}
$$

Where,

$\mathrm{Y}$ is the deflection load at any fatigue loading cycle,

$\mathrm{X}$ is Number of fatigue cycle,

$A_{1}$ is a suitable constant arrived from curve fitting tool,

$\mathrm{t}$ is considered as decay constant,

$\mathrm{Y}_{0}$ is considered as the residual bending load after pivoting state occurrence in the sample after considerable number of fatigue cycles.

The data generated from fatigue test rig is the instantaneous bending load of the given specimen in the form of voltage is processed and plotted as number of fatigue cycles versus instantaneous bending load. The data were plotted for the specimens with orientation sequence of reinforcement staking of $[ \pm 0]_{8},[ \pm 20]_{8},[ \pm 30]_{8},[ \pm 40]_{8},[ \pm 45]_{8},[ \pm 55]_{8}$ and $[ \pm 60]_{8}$ cross ply laminates. The failure behavior of each specimen is discussed referring to the plots obtained in chapter 6

Similarly in the same way we have to conduct the experimentation especially on some specimens $[ \pm 0]_{8},[ \pm 55]$ ${ }_{8}$ and $[ \pm 60]_{8}$ cross ply laminates at different frequencies i.e., at 94, 127, 200 RPM. At these three frequencies we have to take the readings and compare the stiffness degradation of different specimens with respect to speed of the machine. 
And at how many cycles particular specimen is getting Pivoting state $\left(\mathrm{Y}_{0}\right)$ Occurrence. $\mathrm{Y}_{0}$ is considered as the residual bending load after pivoting state occurrence in the sample after considerable number of fatigue cycles.

\subsubsection{Flexural Fatigue Failure Behavior of $\left[ \pm 0^{0}\right]_{8}$}

\section{Laminate}

For the laminate $\left[ \pm 0^{0}\right]_{8}$ exhibits increasing stiffnessreduction up to 10,000 cycles and then a steadily reduction in stiffness up to 30,000 cycles then the reduction is zero due to the pivoting state occurrence. From the Table no. 6.1 it is clear that the bending resisting force is dropped from 320 Newton to 65.93524 Newton and attained pivoting state were further reduction in stiffness is almost zero. After reaching pivoting state the retained stiffness in the specimen is $9.62 \%$ of the virgin specimen at 90 RPM. For 127 RPM the bending resisting force is dropped from 320 Newton to 3.81612 in 9713 cycles. And At $200 \mathrm{rpm}$ for 0 degree orientation specimen the failure is taking place at very early stage. So that it is not possible to take the reading. And from the graphs we can clearly say that as the speed increases the no. of cycles needed to break the specimen decreases i.e., the stiffness degradation is taking place very fastly and pivoting state has occurred after 20000 cycles for 90 RPM and before 1000 cycles for 127 RPM.

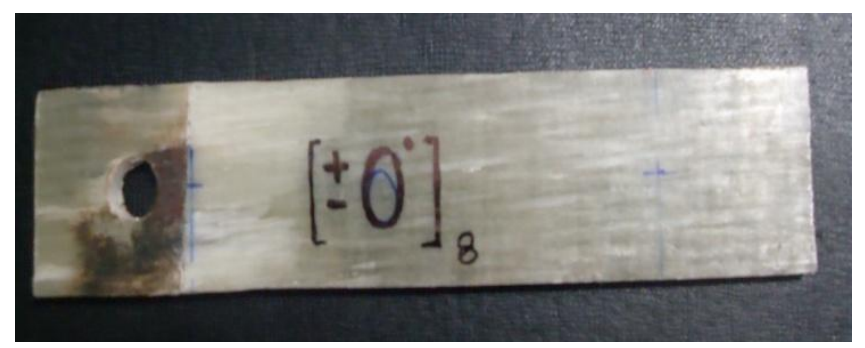

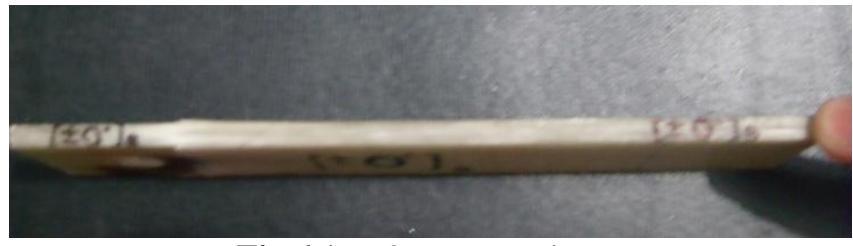

Fig 6.1. $[ \pm 0]_{8}$ test specimen

\begin{tabular}{|l|c|c|c|c|c|}
\hline 525.95 & 114.767 & 324.36 & 62.88 & 146.6652 & 20.52857 \\
\hline 717.49 & 112.639 & 368.88 & 41.88 & 189.9981 & 19.44015 \\
\hline 882.34 & 111.929 & 409.16 & 23.37 & 229.9977 & 18.03485 \\
\hline 1033.06 & 111.486 & 443.08 & 16.02 & 273.3306 & 17.11173 \\
\hline 1212.04 & 111.131 & 506.68 & 13.08 & 316.6635 & 16.54685 \\
\hline 1403.58 & 110.155 & 542.72 & 11.75 & 363.3297 & 14.89354 \\
\hline 1579.42 & 110.067 & 583 & 11.08 & 406.6626 & 12.59269 \\
\hline 1758.4 & 105.366 & 633.88 & 10.39 & 446.6622 & 9.768304 \\
\hline 1956.22 & 105.011 & 669.92 & 10.12 & 489.9951 & 5.910577 \\
\hline 2199.57 & 104.834 & 712.32 & 9.88 & 529.9947 & 2.755501 \\
\hline
\end{tabular}

In the above spread sheet

Table No. 6.1 Stiffness degradation data of $[ \pm 0]$ orientation with cross ply orientation sequence of stacking at $90 \mathrm{rpm}$.

Table No. 6.2 Stiffness degradation data of $[ \pm 0]$ orientation with cross ply orientation sequence of stacking at $127 \mathrm{rpm}$.

Table No. 6.3 Stiffness degradation data of [ \pm 55$]$ orientation with cross ply orientation sequence of stacking at $90 \mathrm{rpm}$.

Table No. 6.4 and 6.5 are the Stiffness degradation data of [ \pm 55$]$ orientation with cross ply orientation sequence of stacking at 127 and $200 \mathrm{rpm}$.

Table No. 6.6, 6.7, and 6.8 are the Stiffness degradation data of $[ \pm 60]$ orientation with cross ply orientation sequence of stacking at 90,127 and $200 \mathrm{rpm}$.

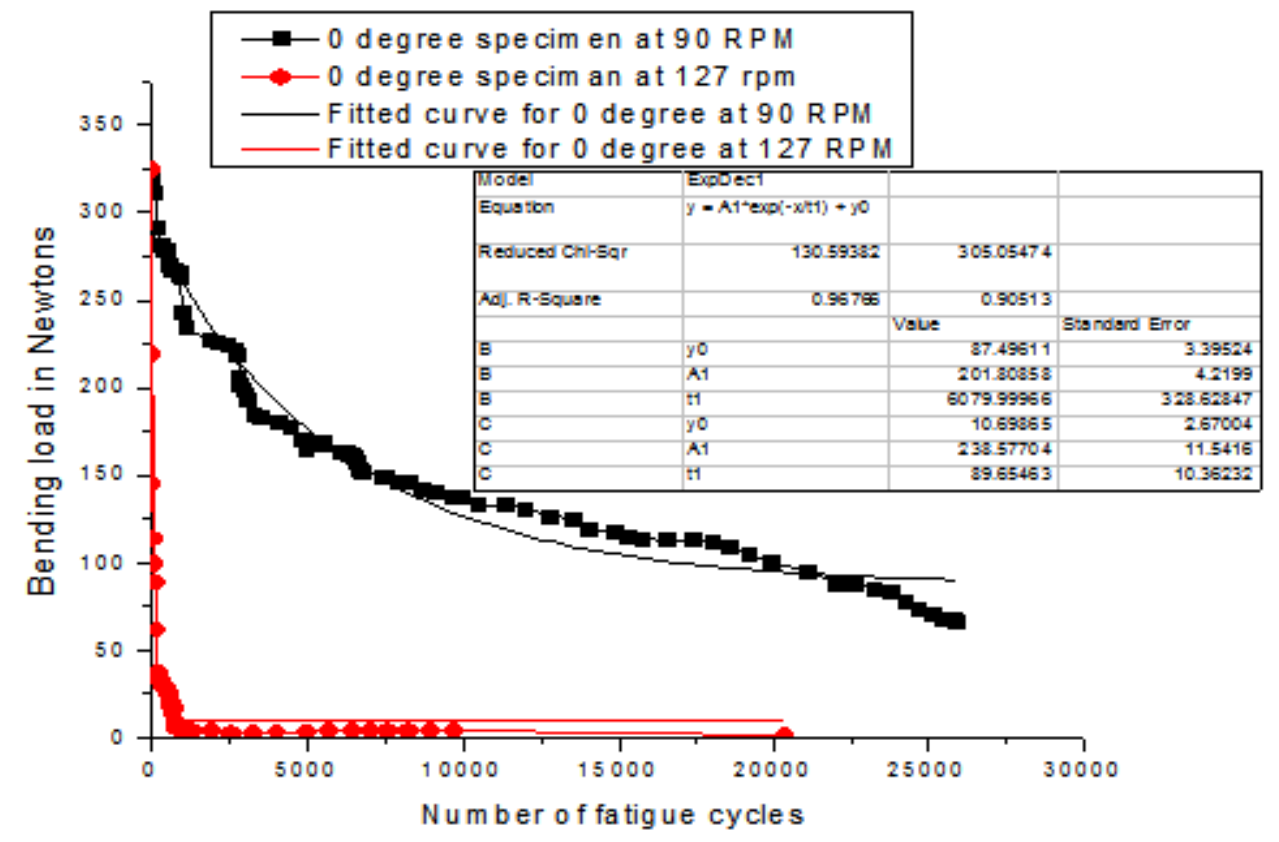

Fig 6.2 Stiffness degradation behavior of $[ \pm 0]$ orientation with cross ply orientation sequence of stacking at 90 and $127 \mathrm{rpm}$ 


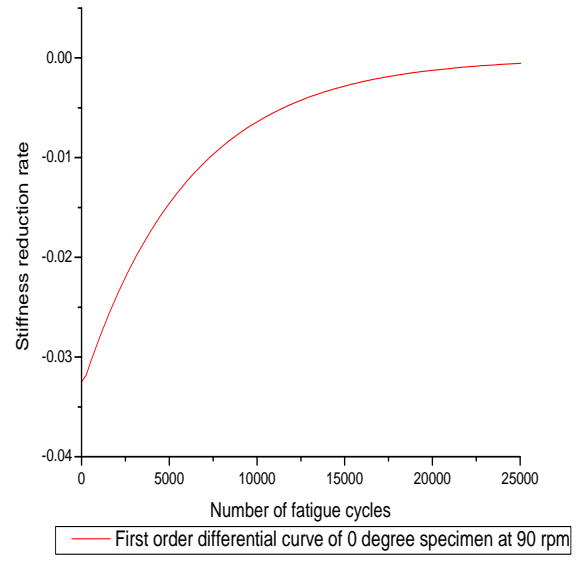

Fig 6.21

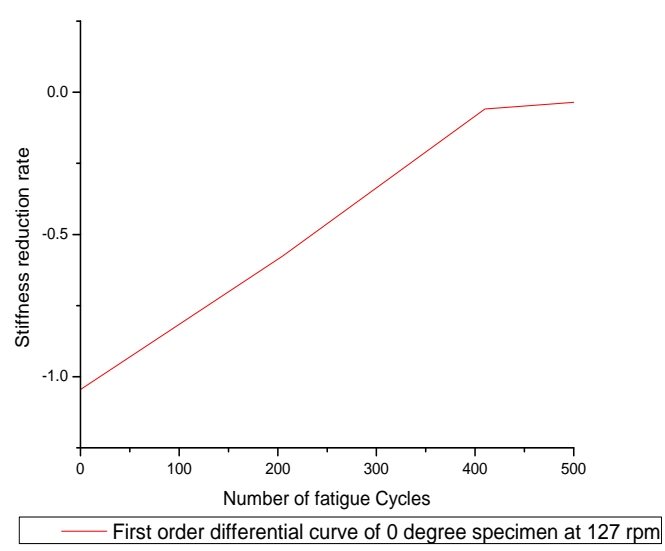

Fig 6.22

Fig 6.21 and 6.22 are the First order differential curves of $\left[ \pm 0^{0}\right]_{8}$ orientation derived from fig. no.6.2

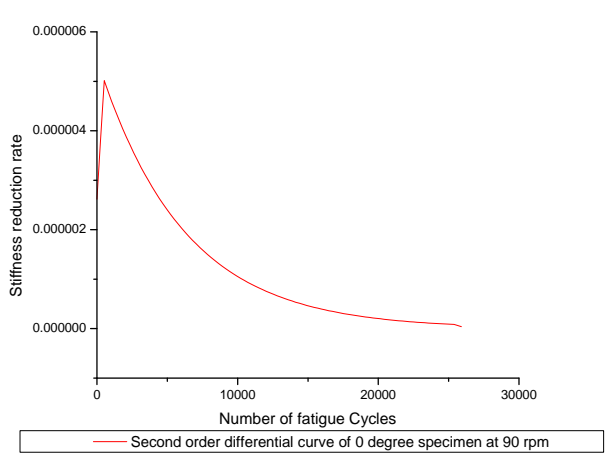

Fig .6.23

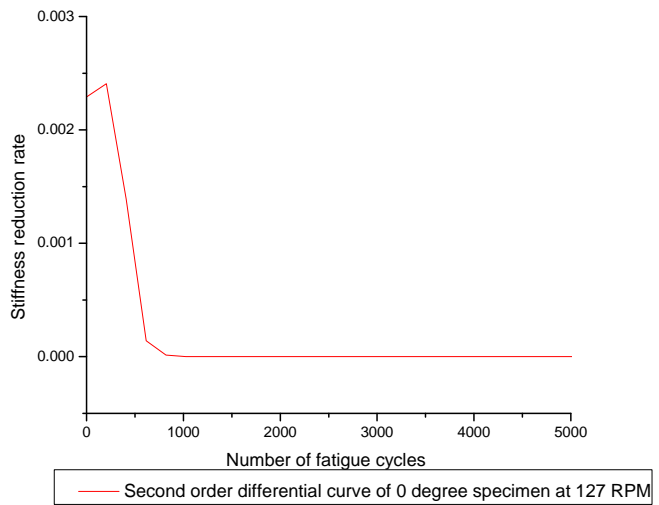

Fig 6.24

Fig 6.23 and 6.24 are the Second order differential curves of $\left[ \pm 0^{0}\right]_{8}$ orientation derived from fig. no.6.2

\subsubsection{Flexural Fatigue Failure Behavior of $\left[ \pm 5^{0}\right]_{8}$}

\section{Laminate:}

The following curve Fig no.6.4 which is drawn with reference to the laminate $\left[{ }^{2} 55^{\circ}\right]_{8}$ exhibits in increasing stiffness reduction up to 1300 cycles and then the reduction in stiffness steadily reduces with reference to the number of cycles up to 30,000 cycles then the reduction is constant due to the pivoting state occurrence. From the Fig no. 6.3 it is clearly evident that the bending resisting force is dropped from 80 Newton to 61 Newton and attained pivoting state where further reduction in stiffness is almost zero. From this result it is clearly evident that the test coupon retained $71.66 \%$ stiffness of the virgin specimen even after 30,000 of fatigue cycles for 90 RPM. And at 127 RPM the stiffness is reduced to 4.684831 Newton from 80 newton in 9646 cycles. And for $200 \mathrm{RPM}$ the stiffness is reduced to 2.350713 Newton from 80 Newton in 2645 cycles. From the results it is clear that the stiffness of this specimen is degrading very slowly when compared to other orientation specimens. For 55 degree specimen pivoting state will occur at large number of cycles why because this specimen stands on the test-rig after many no. of cycles with some internal layers failure.

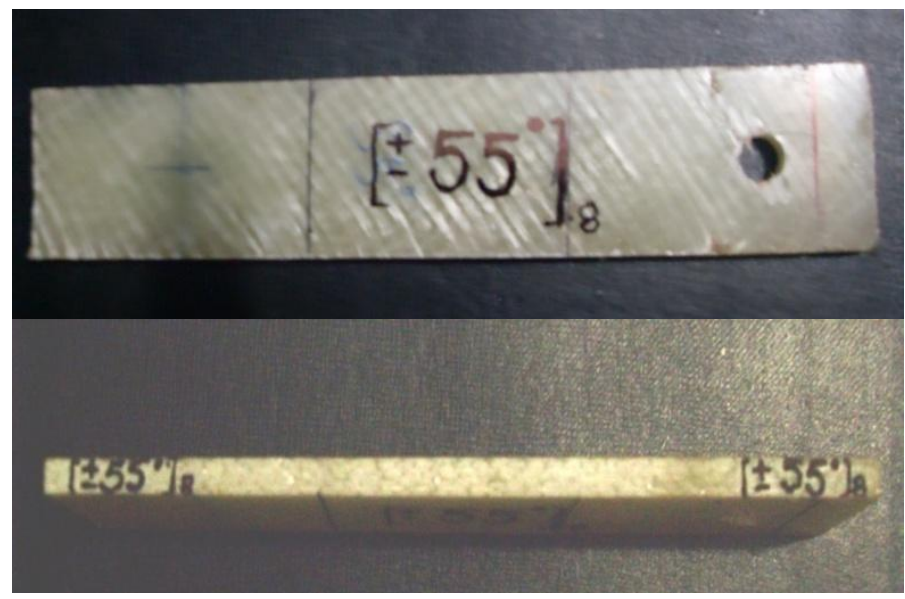

Fig $6.3[ \pm 55]_{8}$ test specimen 


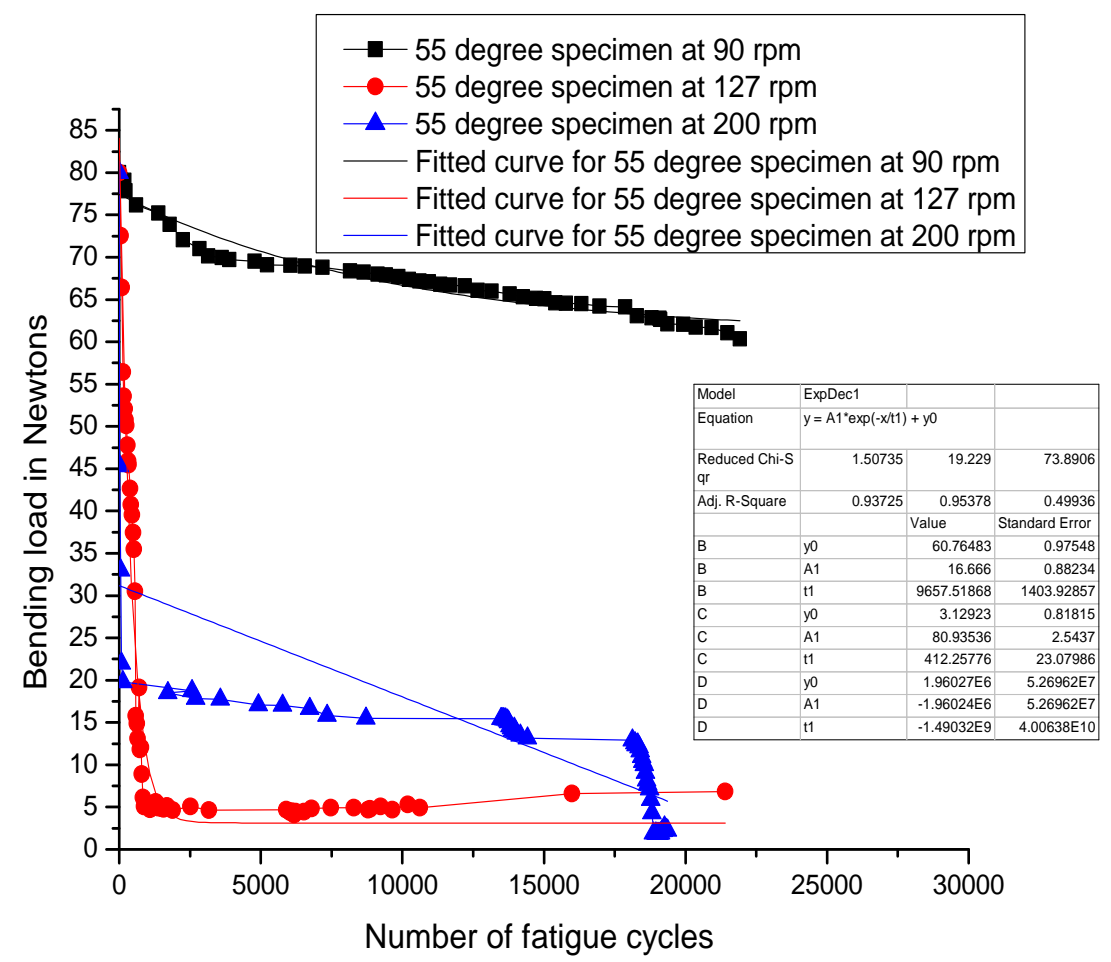

Fig 6.4 Stiffness degradation behavior of $[ \pm 55]$ orientation Laminate with cross ply orientation sequence of stacking

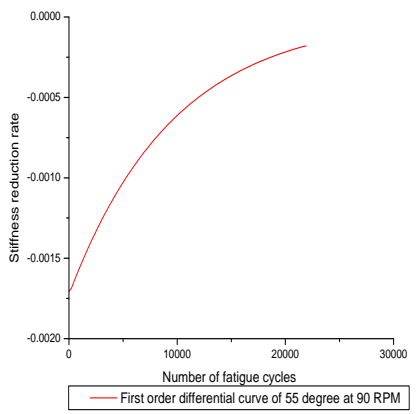

Fig 6.42 Stiffness degradation behavior of $[ \pm 55]$ orientation Laminate with cross ply orientation sequence of stacking at $127 \mathrm{RPM}$

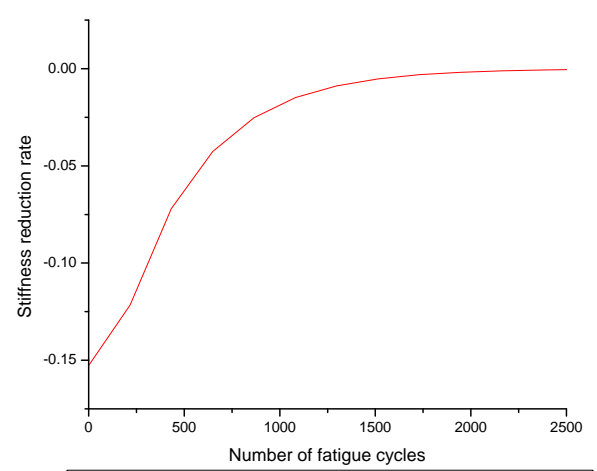

Fig. 6.43 Stiffness degradation behavior of $[ \pm 55]$ orientation Laminate with cross ply orientation sequence of stacking at 90 RPM

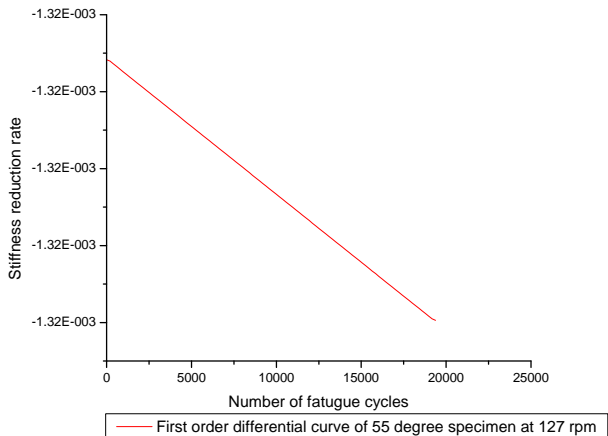

Fig 6.41 Stiffness degradation behavior of [ \pm 55$]$ orientation Laminate with cross ply orientation sequence of stacking at $90 \mathrm{RPM}$

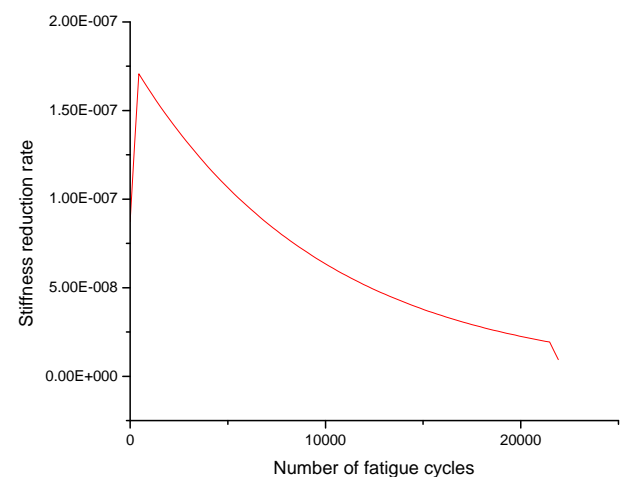

Second order differential curve of 55 degree specimen at $90 \mathrm{rpm}$

Fig. 6.44 Second order differential curve of

$[ \pm 55]$ orientation Laminate with cross ply orientation sequence of stacking at 200 RPM 


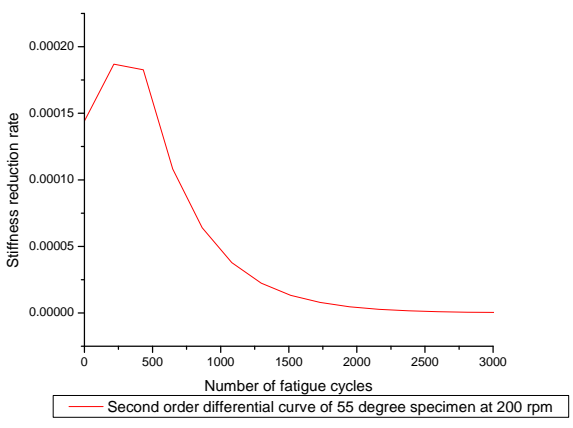

Fig. no.6.45 Second order differential curve of $[ \pm 55]$ orientation Laminate with cross ply orientation sequence of stacking at 127 RPM

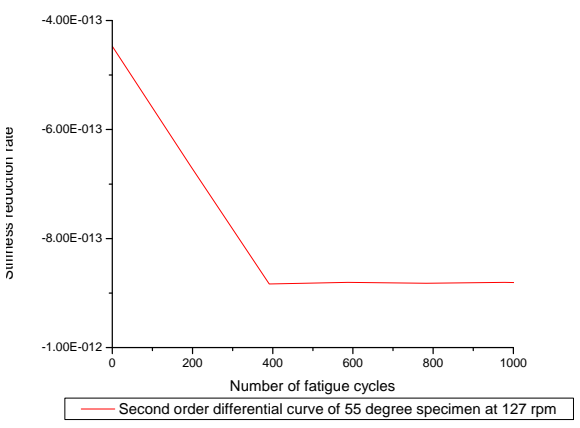

Fig. no.6.46 Second order differential curve of [ \pm 55$]$ orientation Laminate with cross ply orientation sequence of stacking at 200 RPM

Newton in 24432 cycles and for 200 RPM the stiffness reduction is from 120 Newton to 7.150554 in 21146 cycles.

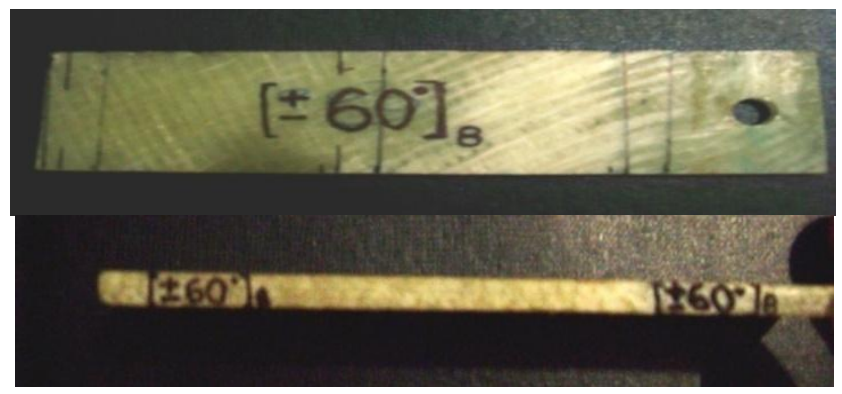

Fig. 6.5 $[ \pm 60]_{8}$ test Specimen

\subsubsection{Flexural Fatigue Failure Behaviour of $\left[ \pm 60^{0}\right]_{8}$}

\section{Laminate}

The following curve Fig no.6.6 which is the laminate $\left[ \pm 60^{0}\right]_{8}$ exhibits in increasing stiffness reduction up to 1250 cycles and then the reduction in stiffness steadily reduces with reference to number of cycles up to 55,000 cycles then the reduction is constant due to the pivoting state occurrence. From the Table 6.6 and Fig 6.6 clearly evident that the bending resisting force is dropped from 120 Newton to 48.56 Newton and attained pivoting state. Then the further reduction in stiffness is almost zero. the reduction rate is almost zero after the pivoting state. From this it can be concluded that the pivoting state is attained at $40.5 \%$ stiffness of the virgin stiffness of the specimen. For 127 RPM the stiffness reduction is from 120 Newton to 4.938

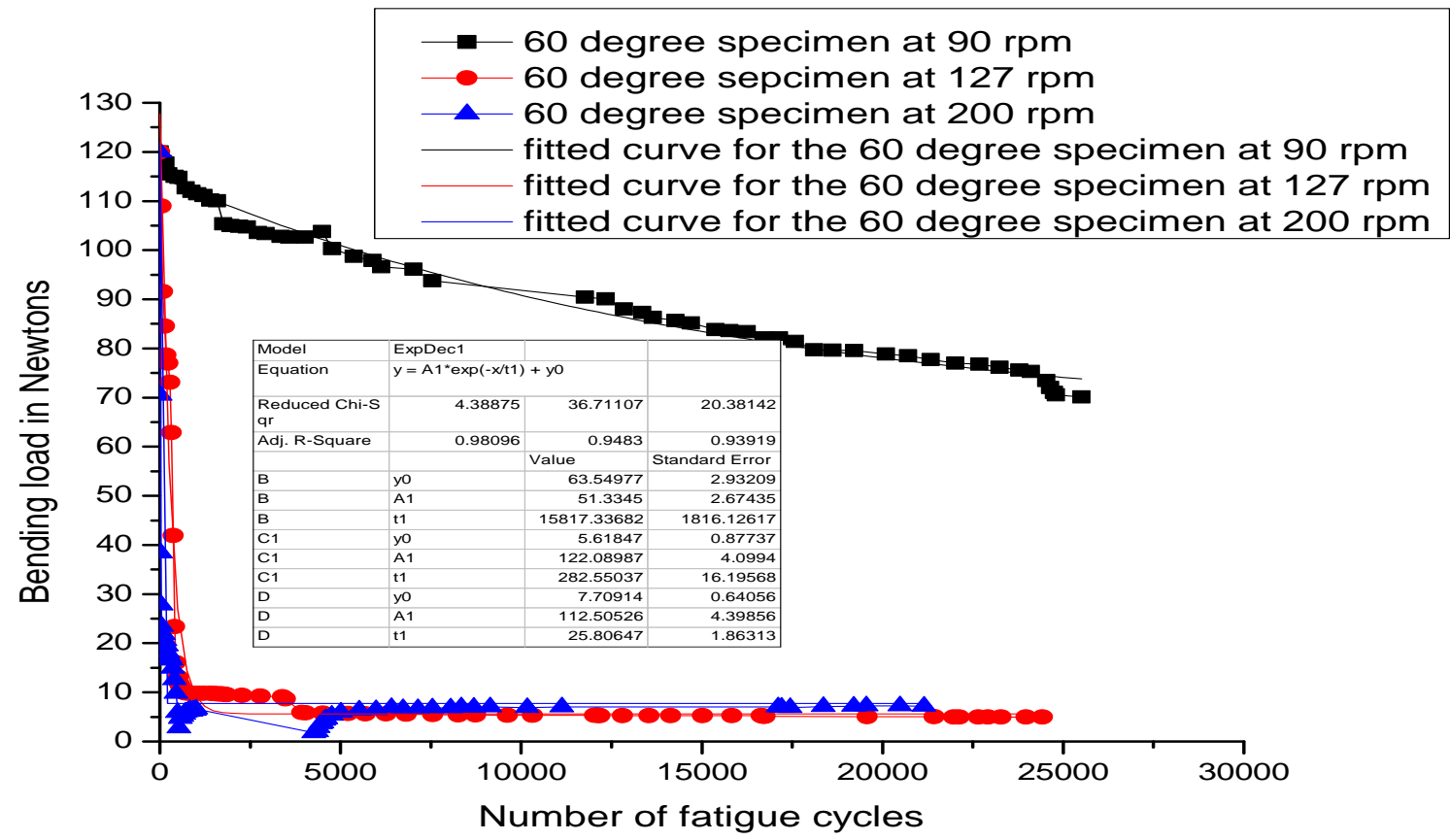

Fig. 6.6 Stiffness degradation behavior of $[ \pm 60]$ orientation Laminate with cross ply orientation sequence of stacking at 90,127 and $200 \mathrm{rpm}$ 


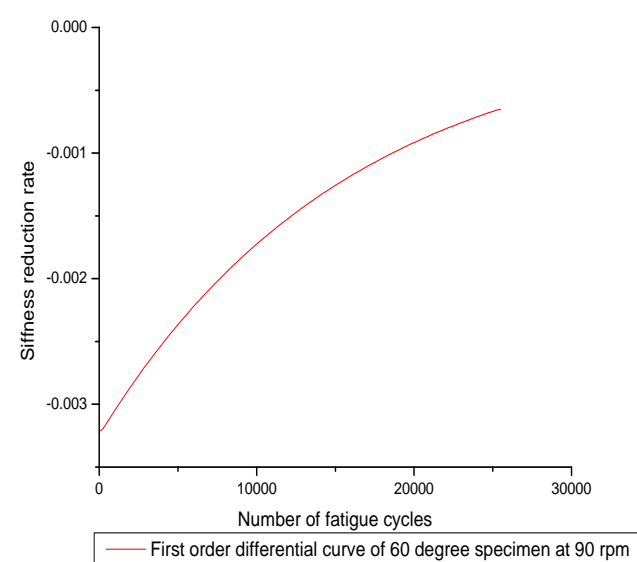

Fig.6.61 Stiffness degradation behavior of $[ \pm 60$ ] orientation Laminate with cross ply orientation sequence of stacking at $90 \mathrm{RPM}$

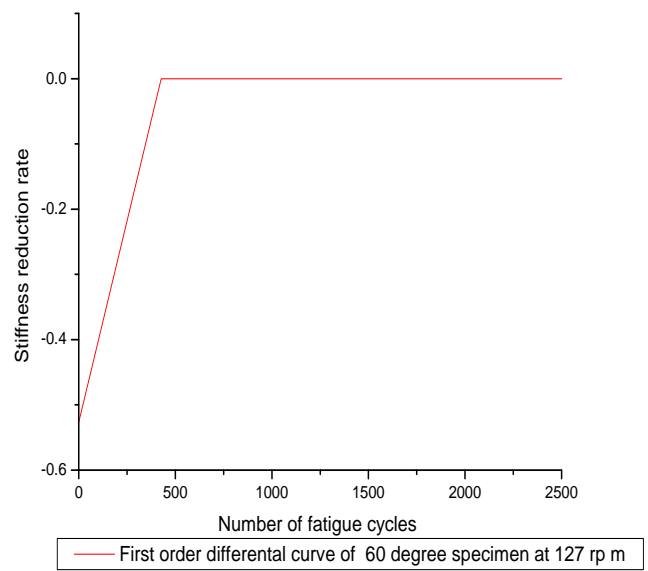

Fig.6. 62 Stiffness degradation behavior of $[ \pm 60$ ] orientation Laminate with cross ply orientation sequence of stacking at $127 \mathrm{rpm}$

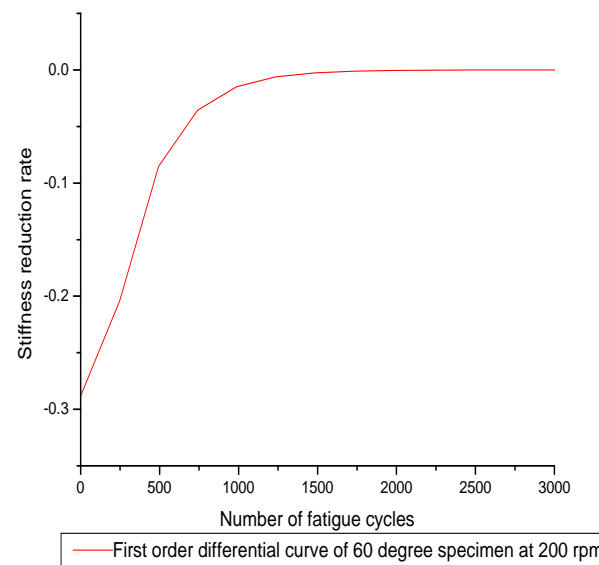

Fig.6.64 Second order differential curve of $[ \pm 60]$ orientation Laminate with cross ply orientation sequence of stacking at 90 RPM

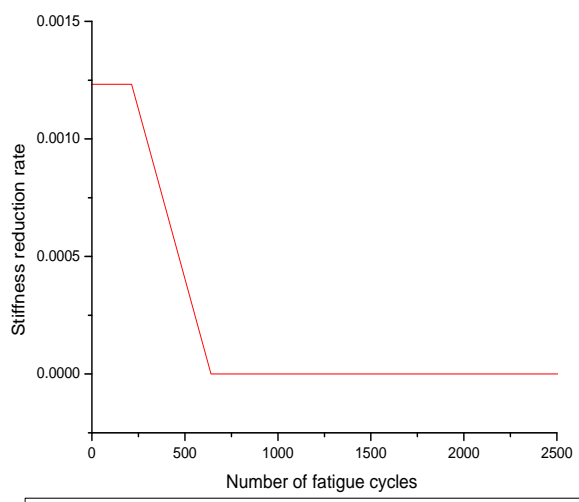

- Second order differential curve of 60 degree specimen at 127 RPM

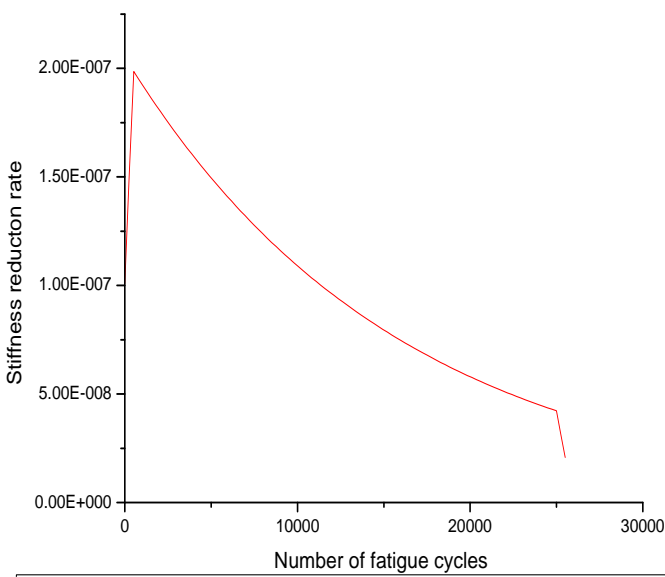

- Second order differential curve of 60 degree specimen at $90 \mathrm{rpm}$

Fig. 6.63 Stiffness degradation behavior of $[ \pm 55]$ orientation Laminate with cross ply orientation sequence of stacking 200 RPM

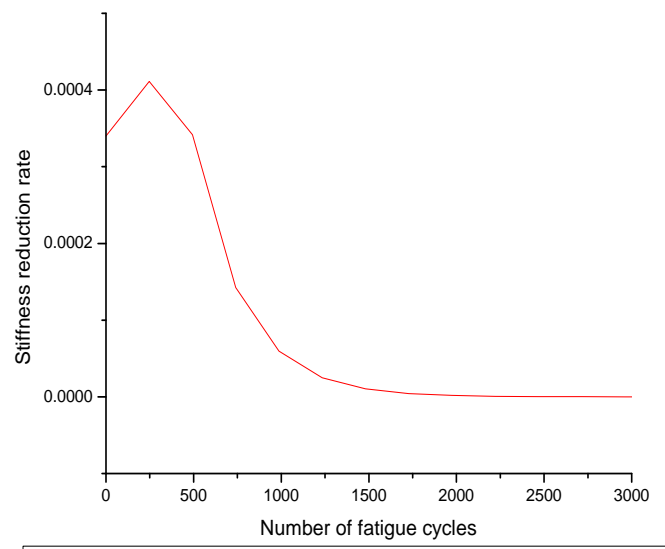

- Second order differential curve of 60 degree specimen at $200 \mathrm{rpm}$

Fig. 6.65, 6.66 are the Second order differential curve of $[ \pm 60]$ orientation Laminate with cross ply orientation sequence of stacking at 127 and 200 RPM 


\section{CONCLUSIONS}

After experimentation finally we are concluding that, at different frequencies degradation takes place differently. If speed increases (frequency) the time required for failure or damage decreases. If speed decreases (frequency) the time required for failure or damage increases. If we increase the speed of the machine i.e., the frequency then the deterioration also take place very fastly. The specimen degraded quickly layer by layer.For 0 degree specimen it takes approximately 3-5 hours at $90 \mathrm{rpm}$, for the same at $127 \mathrm{rpm}$ it takes 2 hour, for the same at $200 \mathrm{rpm}$ it breaks in a few minutes. With respect to frequency the specimen layers are degrading. For different orientation of specimens $(0,55,60)$ the degradation is taking place differently. 0 degree specimen is not able to withstand for high frequencies 55 degree specimen is standing for long time even though the speed is varying and load is increasing. 60 degree specimen is also standing but for a lower number of cycles, if the numbers of cycles are increasing then it did not withstand. It is getting failed before the 55 degree specimen at the same frequency. So we are Concluding that, at different frequencies also 55 degree specimen is better then 0 , 20,30,45,60 all these fiber orientations.

From the above graphs we are concluding that for 0 degree specimen at $90 \mathrm{rpm}$, to get pivoting state is $900-1000$ cycles, For 0 degree specimen at $127 \mathrm{rpm}$, the number of the number of cycles required to get pivoting state is 25000 cycles. For 0 degree specimen at $200 \mathrm{rpm}$, the number of fatigue cycles required cycles required to get pivoting state is not determined because the specimen had broken in the early stage of experimentation. For 55 degree specimen at $90 \mathrm{rpm}$, the number of cycles required to get pivoting state is 100000 cycles, For 55 degree specimen at $127 \mathrm{rpm}$, the number of cycles required to get pivoting state is 20000 cycles, for 55 degree specimen at $200 \mathrm{rpm}$, the number of cycles required to get pivoting state is 2500 cycle. For 60 degree specimen at $90 \mathrm{rpm}$, the number of cycles required to get pivoting state is 20000 cycle, For 60 degree specimen at $127 \mathrm{rpm}$, the number of cycles required to get pivoting state is $500-600$ cycle For 60 degree specimen at $200 \mathrm{rpm}$, the number of cycles required to get pivoting state is below 500 cycle.

\section{REFERENCES}

[1] Levon Minnetyan, Computational Simulation of Composite Structural Fatigue, NASA/CR-2005213573, February 2005.

[2] Van Paepegem, W. and Degrieck, J. (2002). Coupled Residual Stiffness and Strength Model for Fatigue of Fibre-reinforced Composite Materials. Composites Science and Technology, 62(5), 687696.

[3] Van Paepegem, W. and Degrieck, J. (2001), Experimental Setup for and Numerical Modelling of Bending Fatigue Experiments on Plain Woven Glass/epoxy Composites. Composite Structures, 51(1), 1-8.

[4] Van Paepegem, W., Dechaene, R. and Degrieck, J.
(2005). Nonlinear correction to the bending stiffness of a damaged composite beam. Composite Structures, 67(3), 359-364.

[5] Van Paepegem, W., De Geyter, K., Vanhooymissen, P. and Degrieck, J. (2006). Effect Of friction on the hysteresis loops from three-point bending fatigue tests of fibre-reinforced composites.Composite Structures, 72(2), 212-217.

[6] Van Paepegem, W., Degrieck, J. and De Baets, P. (2001). Finite Element Approach for Modelling Fatigue Damage in Fibre-reinforced Composite Materials. Composites Part B, 32(7), 575-588.

[7] Van Paepegem, W. and Degrieck, J. (2001). Fatigue Degradation Modelling of Plain Woven Glass/epoxy Composites. Composites Part A, 32(10), 1433-1441.

[8] Van Paepegem, W. and Degrieck, J. (2002). Coupled Residual Stiffness and Strength Model for Fatigue of Fibre-reinforced Composite Materials. Composites Science and Technology, 62(5), $687-$ 696.

[9] Van Paepegem, W. and Degrieck, J. (2002). Tensile and Compressive Damage Coupling for Fullyreversed Bending Fatigue of Fibre- reinforced Composites. Fatigue and Fracture of Engineering Materials \& Structures, 25(6), 547-562.

[10] Van Paepegem, W. and Degrieck, J. (2002). A New Coupled Approach of Residual Stiffness and Strength for Fatigue of Fibre-reinforced Composites. International Journal of Fatigue, 24(7), 747-762.

[11] A. Bernasconi ${ }^{\text {a, }}$, S. Foletti ${ }^{\text {a }}$ I.V. Papadopoulos ${ }^{\text {b }}$, Multiaxial Fatigue Tests Under Combined Torsion And Axial Load With Different Frequencies, Xxxiv Convegno Nazionale — 14-17 September 2005, POLITECNICO DI MILANO.

[12] Leihong $\mathrm{Li}$, structural design of composite rotor blades with consideration of manufacturability, durability, and manufacturing uncertainties, A Thesis Submitted in Partial Fulfillment of the Requirements for the Degree Doctor of Philosophy in the School of Aerospace Engineering Georgia Institute of Technology August 2008.

[13] Darris White,New Method for Dual-Axis Fatigue Testing of Large Wind Turbine Blades Using Resonance Excitation and Spectral Loading, NREL/TP-500-35268, April 2004.

[14] Levon Minnetyan, Computational Simulation of Composite Structural Fatigue, NASA/CR-2005213573, February 2005.

[15] Sanjay Mathur2 Prakash Chandra Gope1 and J. K. Sharma1, Prediction of Fatigue Lives of Composites Material by Artificial Neural Network, Paper 260, Proceedings of the SEM 2007 Annual Conference and Exposition, Springfield, Massachusetts, USA, June 4-6, 2007, Copyright Society for Experimental Mechanics, Inc., Bethel, CT USA (2007). 


\section{BIOGRAPHIES}

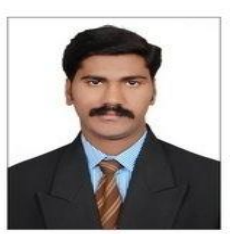

Vijaykiran Bura, Asstant Professor,

Padmashri Dr.B.V.Raju Institute of

Technology (BVRIT), Narsapur.

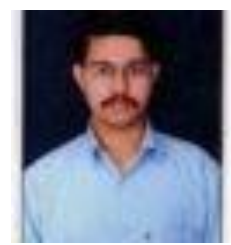

Praveen.Dvr, Asstant Professor,

Padmashri Dr.B.V.Raju Institute of

Technology (BVRIT), Narsapur. 